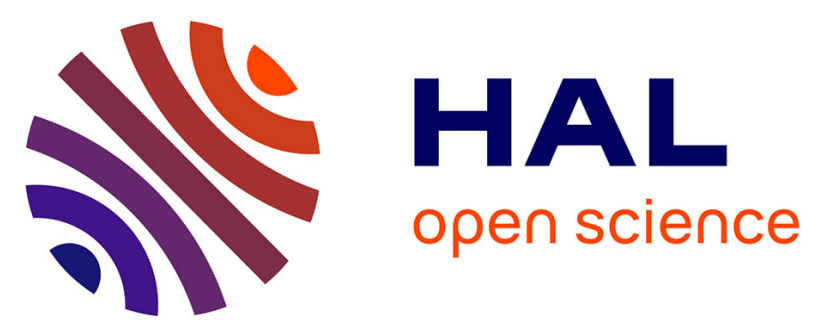

\title{
Biochemical disorders induced by cytotoxic marine natural products in breast cancer cells as revealed by proton NMR spectroscopy-based metabolomics
}

Mathilde Bayet-Robert, Suzanne Lim, Chantal Barthomeuf, Daniel Morvan

\section{- To cite this version:}

Mathilde Bayet-Robert, Suzanne Lim, Chantal Barthomeuf, Daniel Morvan. Biochemical disorders induced by cytotoxic marine natural products in breast cancer cells as revealed by proton NMR spectroscopy-based metabolomics. Biochemical Pharmacology, 2010, 80 (8), pp.1170. 10.1016/j.bcp.2010.07.007 . hal-00618177

\section{HAL Id: hal-00618177 \\ https://hal.science/hal-00618177}

Submitted on 1 Sep 2011

HAL is a multi-disciplinary open access archive for the deposit and dissemination of scientific research documents, whether they are published or not. The documents may come from teaching and research institutions in France or abroad, or from public or private research centers.
L'archive ouverte pluridisciplinaire HAL, est destinée au dépôt et à la diffusion de documents scientifiques de niveau recherche, publiés ou non, émanant des établissements d'enseignement et de recherche français ou étrangers, des laboratoires publics ou privés. 


\section{Accepted Manuscript}

Title: Biochemical disorders induced by cytotoxic marine natural products in breast cancer cells as revealed by proton NMR spectroscopy-based metabolomics

Authors: Mathilde Bayet-Robert, Suzanne Lim, Chantal Barthomeuf, Daniel Morvan

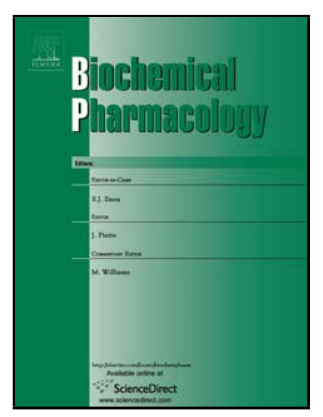

PII: S0006-2952(10)00518-6

DOI: doi:10.1016/j.bcp.2010.07.007

Reference: BCP 10640

To appear in: $\quad B C P$

Received date: $\quad 20-5-2010$

Revised date: $\quad$ 5-7-2010

Accepted date: $\quad$ 7-7-2010

Please cite this article as: Bayet-Robert M, Lim S, Barthomeuf C, Morvan D, Biochemical disorders induced by cytotoxic marine natural products in breast cancer cells as revealed by proton NMR spectroscopy-based metabolomics, Biochemical Pharmacology (2010), doi:10.1016/j.bcp.2010.07.007

This is a PDF file of an unedited manuscript that has been accepted for publication. As a service to our customers we are providing this early version of the manuscript. The manuscript will undergo copyediting, typesetting, and review of the resulting proof before it is published in its final form. Please note that during the production process errors may be discovered which could affect the content, and all legal disclaimers that apply to the journal pertain. 


\section{Biochemical disorders induced by cytotoxic marine natural products in}

\section{breast cancer cells as revealed by proton NMR spectroscopy-based metabolomics}

Mathilde Bayet-Robert ${ }^{\mathrm{a}, \mathrm{b}}$, Suzanne Lim ${ }^{\mathrm{a}}$, Chantal Barthomeuf ${ }^{\mathrm{a}}$, Daniel Morvan ${ }^{\mathrm{a}, \mathrm{b} *}$

${ }^{a}$ Université d'Auvergne, 28 place Henri Dunant, 63001 Clermont-Ferrand, France

${ }^{\mathrm{b}}$ Centre de lutte contre le cancer Jean Perrin, 58 rue Montalembert, 63011 Clermont-Ferrand, France

*Corresponding author at: Faculté de Médecine et Pharmacie, 28 place Henri Dunant, 63001 Clermont-Ferrand, France. Tel.: +33473178130; Fax: +33473178139; E-mail address: Daniel.MORVAN@u-clermont1.fr (D. Morvan)

Short title: Metabolomics of MCF7 cell response to marine natural products

\footnotetext{
Abbreviations: Asc, Ascididemin; Lam-D, Lamellarin-D; KF, Kahalalide F; MNP, Marine natural product; HRMAS, High resolution magic angle spinning; ${ }^{1} \mathrm{H}-\mathrm{NMR}$, Proton nuclear magnetic resonance.
} 


\begin{abstract}
Marine plants and animals are sources of a huge number of pharmacologically active compounds, some of which exhibit antineoplastic activity of clinical relevance. However the mechanism of action of marine natural products (MNPs) is poorly understood. In this study, proton NMR spectroscopy-based metabolomics was applied to unravel biochemical disorders induced in human MCF7 breast cancer cells by 3 lead candidate anticancer MNPs: ascididemin (Asc), lamellarin-D (Lam-D), and kahalalide F (KF). Asc, Lam-D, and KF provoked a severe decrease in DNA content in MCF7 cells after $24 \mathrm{~h}$ treatment. Asc and Lam-D provoked apoptosis, whereas KF induced non-apoptotic cell death. Metabolite profiling revealed major biochemical disorders following treatment. The response of MCF7 tumor cells to Asc involved the accumulation of citrate $(\times 17$ the control level, $P<0.001)$, testifying enzyme blockade in citrate metabolism, and the accumulation of gluconate $(\times 9.8, P$ $<0.005)$, a metabolite never reported at such concentration in tumor cells, probably testifying glycolysis shutdown. The response to Lam-D involved the accumulation of aspartate $(\times 7.2, P$ $<0.05)$, glutamate $(\times 14.7, P<0.05)$, and lactate $(\times 2.3, P<0.05)$, probably in relation with the targeting of the malate-aspartate shuttle, as discussed. The response to KF involved increased lipid accumulation (polyunsaturated fatty acids $\times 9.8, P<0.05$ ), and phospholipid and acetate derivative alterations. Altogether, this study demonstrates the potential of proton NMR spectroscopy-based metabolomics to help uncover metabolic targets and elucidate the mechanism of cytotoxicity of candidate antineoplastic MNPs.
\end{abstract}

Keywords: Marine natural products; MCF7 breast tumor cells; Apoptosis; NMR spectroscopy-based metabolomics; Metabolic targets. 


\section{Introduction}

There is a wide diversity of marine plants and animals from which a huge number of pharmacologically active compounds have been isolated. Given their potent cytotoxicity, structural diversity, and mechanistic complexity, marine natural products (MNPs) recognized as clinically relevant antineoplastic agents are much less numerous [1]. Among small peptides and alkaloids, some have entered phase I and II clinical trials [1, 2], and very few are approved as orphan drugs by the European Commission and the Food and Drug Administration, including trabectedin in combination with doxorubicin for the treatment of platinum-sensitive recurrent ovarian cancer, and dehydrodidemnin B as a monotherapy for acute lymphoblastic leukemia and for multiple myeloma. However the mechanism of action of candidate antineoplastic MNPs remains greatly unknown. There is growing interest in metabolomics for investigating the molecular mechanism of action of drugs and identifying enzyme or metabolic pathways as targets for these agents [3-5]. We sought to exploit advances in high resolution magic angle spinning (HRMAS) proton nuclear magnetic resonance (NMR) spectroscopy-based metabolomics [6] to get novel insights into the biochemical mechanism of action of 3 lead candidate anticancer MNPs: ascididemin (Asc), lamellarin-D (Lam-D), and kahalalide F (KF) in human MCF7 breast cancer cells.

Asc, a pyridoacridine alkaloid, displays an activity of topoisomerase II inhibitor and provokes strong antiproliferative effects on human and murine leukemia cell lines $[7,8]$. The mechanism of Asc-induced cell death was shown to implicate mitochondrial reactive oxygen species (ROS) production related to the reduction of the iminoquinone moiety of Asc, and DNA break formation [9]. Asc yields oxidative stress-dependent apoptosis through JNKdependent activation of caspase-2 [7, 10].

Lam-D, a pyrrole alkaloid, induces apoptotic cell death through stabilization of topoisomerase I-DNA covalent complexes, induction of DNA damage, and early disruption of the inner 
mitochondrial transmembrane potential (MTP) in human breast and lung carcinoma cell lines [11]. It was also shown to inhibit several kinases relevant to cancer such as cyclin-dependent kinases [12]. Pyrrole-derived alkaloids of which Lam-D have been found to be potent inhibitors of ATP-citrate lyase (ACL, E.C.2.3.3.8) [13] and exhibit an in vitro aldose reductase (ALR2, E.C.1.1.1.21) inhibitory activity [14].

KF, a cycle depsipeptide, displays antitumor activity against breast, ovary, prostate and colon cancer cell lines [15]. KF interacts with lipid membranes [15] and cell lysosomes, induces the formation of large vacuoles in treated cell cultures [16], and provokes oncosis in human prostate and breast cancer cells [17]. KF has recently been studied in phase I clinical trial in advanced androgen refractory prostate cancer [18] and in phase II trial in advanced malignant melanoma [19].

The aim of this study was to use proton NMR spectroscopy-based metabolomics to uncover biochemical disorders induced by Asc, Lam-D and KF in MCF7 breast cancer cells, and help identify metabolic targets and cytotoxicity mechanism of these candidate antitumor agents in relation with literature data. Our data reveal metabolic alterations in response to these MNPs that may be assigned to molecular targets. These new metabolic endpoints may serve the design of MNP-evaluating clinical trials in breast cancer.

\section{Material and methods}

\subsection{Chemicals and reagents}

The pyridoacridine alkaloid Asc was a gift from Bernard Banaigs (Laboratoire de Chimie des Biomolécules et de l'Environnement, Perpignan, France). The pyrrole alkaloid Lam-D and the small natural peptide KF were manufactured by PharmaMar (Madrid, Spain).

Each MNP was solubilized in dimethylsulfoxide (DMSO, Merckeurolab, Strasbourg, France) immediately before use in the culture medium. The DMSO concentration was maintained at a 
final concentration of $0.5 \%$. Eagle's MEM-Glutamax medium, MEM vitamin solution, sodium pyruvate, non essential amino acids, phosphate buffered saline solution (PBS), gentamicin base, and propidium iodide were purchased from Gibco Invitrogen (Cergy Pontoise, France). Fetal calf serum was from Bio West (Nuaillé, France). Sodium dodecyl sulfate and Hoechst 33342 were purchased from Sigma-Aldrich (Saint Quentin Fallavier, France). $\mathrm{D}_{2} \mathrm{O}$ for NMR use was from SDS (Peypin, France).

\subsection{Cell culture and treatment}

Human estrogen-responsive breast adenocarcinoma MCF7 cells were purchased from the European Collection of Cell Culture (Salisbury, UK). Cells were plated in triplicate into 96well plates at a density of $3.5 \times 10^{4}$ cells/well for DNA content measurement, T75 flasks $(1 \times$ $10^{6}$ cells/flask) for quantification of apoptosis and microscopy analysis, or T180 flasks $(10 \times$ $10^{6}$ cells/flask) for NMR spectroscopy analysis. Cells were maintained as a monolayer culture at $37^{\circ} \mathrm{C}$ in humidified atmosphere containing $5 \% \mathrm{CO}_{2}$ in Eagle's MEM-Glutamax medium supplemented with $10 \%$ fetal calf serum, 1\% MEM vitamin solution, $1 \%$ sodium pyruvate, $1 \%$ non essential amino acids, and $0.04 \%$ gentamicine base.

MCF7 cells were exposed to cytotoxic concentrations of MNPs: $5 \mu \mathrm{M}$ Asc, $5 \mu \mathrm{M}$ Lam-D, and $3 \mu \mathrm{M} \mathrm{KF}[7,17,20]$, or the vehicule alone (0.5\% DMSO, control group). At specified times $(4,6,24$, and $48 \mathrm{~h}$ after the onset of treatment), cells were harvested by trypsinization, rinsed once with PBS, then 2 times with $\mathrm{D}_{2} \mathrm{O}$ containing $1 \%$ PBS.

\subsection{DNA content measurement}

DNA content as an index of biomass of attached cells was measured after cell lysis, using Hoescht 33342 staining [21]. Briefly, $100 \mu 1$ of a $0.01 \%$ sodium dodecyl sulfate solution in sterile distilled water was distributed into each well. MCF7 cells were then incubated for $1 \mathrm{~h}$ 
at room temperature and frozen at $-80^{\circ} \mathrm{C}$ for $1 \mathrm{~h}$. After thawing (approximately $15 \mathrm{~min}$ ), 100 $\mu \mathrm{l}$ of Hoechst 33342 solution at $30 \mathrm{mg} / \mathrm{l}$ in a hypersaline buffer $(10 \mathrm{mM}$ Tris- $\mathrm{HCl}, \mathrm{pH} 7.4,1$ mM EDTA, and $2 \mathrm{M} \mathrm{NaCl}$ ) was added to each well. Plates were incubated in this solution for $1 \mathrm{~h}$, and protected from light at room temperature on a plate shaker. Fluorescence was then measured on a microplate fluorometer (Fluoroskan Ascent FL, Thermolabsystem, Helsinki, Finland) using an excitation wavelength of $360 \mathrm{~nm}$, and an emission wavelength of $460 \mathrm{~nm}$.

\subsection{Cellular morphology and quantification of apoptosis}

Cellular morphology was observed by microscopy analysis with fluorescence microscope $(\lambda=$ $365 \mathrm{~nm}$, magnification $60 \times)$ after cell staining with Hoechst $33342(0.5 \mathrm{mg} / \mathrm{l}, 10 \mathrm{~min}$ in the dark). Apoptosis was determined by fluorescence-activated cell sorting (FACS) with a FACScalibur (Becton Dickinson, France) after cell staining with propidium iodide. The percentage of apoptotic cells was quantified as the amount of attached cells in the sub-G1 phase.

\subsection{NMR spectroscopy analysis}

Attached MCF7 cells were collected by centrifugation (1 $500 \mathrm{~g}$ for $10 \mathrm{~min}$ at $4^{\circ} \mathrm{C}$ ). Cell pellets were washed twice with $1 \mathrm{ml} \mathrm{D}_{2} \mathrm{O}$ containing $1 \% \mathrm{PBS}$ and frozen at $-80^{\circ} \mathrm{C}$ until analysis. Five to $10.10^{6}$ intact cells were used for each NMR spectroscopy acquisition.

NMR Spectroscopy was performed on a small bore $500 \mathrm{MHz}$ Avance DRX spectrometer (Bruker Biospin, Karlsruhe, Germany) equipped with a HRMAS probe. Unprocessed cell pellets were set into $4 \mathrm{~mm}$ diameter $50 \mu \mathrm{l}$ free volume zirconium oxide rotor tubes. Rotors were spun at $4 \mathrm{kHz}$, and cooled at $4^{\circ} \mathrm{C}$ using the BCU-05 temperature unit.

One-dimensional (1D) proton NMR spectra were obtained using a Nuclear Overhauser Enhancement spectroscopy sequence with low power water signal presaturation (NOESYPR) 
during both the 3.8 -s relaxation delay and the 100-ms mixing time of the sequence. The spectral width was $12 \mathrm{ppm}$ with $16 \mathrm{~K}$ complex data points and 32 transients. This resulted in 2:50 min acquisition duration. After Fourier transformation, low order phase correction and baseline spline correction were applied in a standardized way. One-dimensional NMR spectra were processed using deconvolution procedures, using the Topspin 2.0 software (Bruker Biospin, Karlsruhe, Germany).

A two-dimensional (2D) NMR spectrum was recorded immediately after the 1D NMR spectrum, using a Total Correlation Spectroscopy (TOCSY) sequence involving water signal suppression at low power, 6-ppm spectral bandwidth along both frequency axes, 256 samples along the first axis, and $2 \mathrm{~K}$ samples along the second axis, $75-\mathrm{ms}$ mixing time during which was applied the spin-lock pulse train (DIPSI-2), 1-s relaxation delay, and 16 repetitions. The 2D NMR spectrum duration was 1:41 hour [22]. TOCSY spectra were reconstructed at both high $(2 \mathrm{~K} \times 256)$ and moderately lower $(256 \times 256)$ spectral resolution for signal attribution and quantification, respectively. Baseline correction was applied using a second order polynomial. Then spectra were transferred on an Excel worksheet (Microsoft Co), and processed using a homebuilt routine designed to automatically compute spectral cross-peak volumes of identified signals. Quantification of metabolite content and variations between treated and control conditions exploited 1D and 2D NMR spectroscopy signals of metabolites, according to the previously published method $[6,23]$. Quantified metabolites are listed in Table 1.

Table 1

\subsection{Data processing and statistical analysis}

Three to 5 independent experiments were performed for each time point. Statistical comparisons between control and treated groups were performed using the nonparametric Mann-Whitney test. Statistical tests were two-tailed unless specified. Differences were considered statistically significant for $P<0.05$. 
To identify NMR spectrum signals which were discriminating between treated and control groups, partial least squares-discriminant analysis (PLS-DA) was applied to $1 \mathrm{D}{ }^{1} \mathrm{H}-\mathrm{NMR}$ spectra using the Tanagra 1.4.23 software (University Lyon2, France). One dimensional ${ }^{1} \mathrm{H}-$ NMR spectra were binned into 0.012 ppm rectangular buckets over the spectral area 4.30-1.10 ppm. The variable importance in the projection (VIP) [24] was calculated for each spectral bucket, and used as the criterion for its discriminating value. The VIP is derived from a ratio of sums of squares, therefore is always positive, even if the signal of the corresponding bucket decreases. A value of the VIP clearly above 1 was required to retain the discriminating power of a spectral bucket.

To assist the identification of unknown metabolites in the response to Asc, statistical TOCSY (STOCSY) [25] was computed from 1D ${ }^{1} \mathrm{H}-\mathrm{NMR}$ spectra. It provided a 2D representation of the square of the statistical correlation coefficient $\left(\mathrm{r}^{2}\right)$ between unknown signals. In case of high correlation between unknown signals, there was presumption that they belonged to the same molecule, which assisted structural elucidation.

As a means of integrating biochemical information in the response to Asc, hierarchical clustering was performed on metabolite data from control and Asc-treated groups using the Spearman's rank correlation and displayed using the Treeview software [26].

\section{Results}

\subsection{Global cytotoxicity to MNPs at selected doses}

The exposure to all studied MNPs (Asc, Lam-D, and KF) yielded decreased DNA content, an index of cell biomass (Fig. 1A). DNA content significantly decreased in attached MCF7 cells after exposure to $5 \mu \mathrm{M}$ Asc, $5 \mu \mathrm{M}$ Lam-D, and $3 \mu \mathrm{M} \mathrm{KF}(30 \% \pm 7 \%, 50 \% \pm 4 \%$, and $44 \% \pm$ $8 \%$, at 24 h respectively, $P<0.01 ; 18 \% \pm 7 \%, 21 \% \pm 1 \%, 15 \% \pm 7 \%$, at 48 h respectively, $P$ <0.01) (Fig. 1A).

Figure 1 
Apoptosis was evaluated from the count of attached cells in the sub-G1 phase. Treatment with Asc yielded massive apoptosis at $24 \mathrm{~h}$ with $63 \% \pm 6 \%(P<0.01)$ apoptotic cells. The count of apoptotic cells at $4 \mathrm{~h}$ and $6 \mathrm{~h}$ was $8 \% \pm 2 \%(P=\mathrm{NS})$ and $21 \% \pm 3 \%(P<0.01)$, respectively (Fig. 1B). The count of apoptotic cells exposed to Lam-D at $4 \mathrm{~h}, 6 \mathrm{~h}$, and $24 \mathrm{~h}$ was $2 \% \pm 1 \%$ $(P=\mathrm{NS}), 15 \% \pm 4 \%(P<0.05)$, and $4 \% \pm 1 \%(P=\mathrm{NS})$, respectively (Fig. 1B). These data indicated that critical metabolic events in MCF7 cells took place before $6 \mathrm{~h}$ in response to Asc and Lam-D.

Apoptosis was confirmed by fluorescence microscopy analysis. After a 6 h-exposure to Lam$\mathrm{D}$ and a $24 \mathrm{~h}$-exposure to $5 \mu \mathrm{M}$ Asc, apoptotic bodies could be seen (Fig. 1C). After $6 \mathrm{~h}$, detached MCF7 cells exposed to Lam-D were observed with neither fluorescence microscopy nor FACS analysis. KF did not lead to apoptotic cell death, but to cell swelling as revealed by optical microscopy (data not shown).

\subsection{Global metabolite variations in MCF7 cell spectra in response to MNPs}

In $1 \mathrm{D}{ }^{1} \mathrm{H}-\mathrm{NMR}$ spectra of Asc-treated cells, intense signals of Cit were visible $4 \mathrm{~h}$ after the onset of treatment. Cit signals increased between 4 and 24 h (Fig. 2). Other obvious metabolite variations were the increase of alanine (Ala) and phosphoethanolamine (PE).

In $1 \mathrm{D}{ }^{1} \mathrm{H}-\mathrm{NMR}$ spectra of Lam-D-treated cells, intense signals of Asp were visible $4 \mathrm{~h}$ after the onset of treatment. Also, there was an increase in Glu, acetate (Ace), Ala, and ethanol (EtOH) after a 6 h-exposure (Fig. 2).

In $1 \mathrm{D}{ }^{1} \mathrm{H}-\mathrm{NMR}$ spectra of KF-treated cells, there was an increase in polyunsaturated fatty acid (PUF) and total fatty acid (tFA) signals $6 \mathrm{~h}$ after the onset of treatment (Fig. 2).

To identify signals which were discriminating between treated and control groups, PLS-DA was performed on $1 \mathrm{D}{ }^{1} \mathrm{H}-\mathrm{NMR}$ spectra (Fig. 3). In response to Asc, ${ }^{1} \mathrm{H}-\mathrm{NMR}$ buckets with a VIP value clearly above 1 corresponded to Cit, glutamine (Gln), Glu, Ala, glycine (Gly), 
taurine (Tau), and PE. Also 5 unknown signals (X1 to X5) exhibited high VIP value and were subject to further analysis for identification. In response to Lam-D, discriminant signals were associated to Lac, Glu, Gly, phosphocholine (PC), Asp, Ala, and EtOH. On KF-treated cell spectra, discriminant signals were associated to PC, glycerophosphoethanolamine (GPE), PUF, and lipids (Fig. 3).

Figure 3

\subsection{Identification of an unusual metabolite accumulating in response to Asc}

PLS-DA revealed 5 new signals (X1 to X5) at 4.13, 4.02, 3.84, 3.82, and 3.76 ppm (Fig. 3). To identify the underling metabolite(s), we first focused on 2D NMR spectra, and identified strong spin system-related correlations at 3.76-4.13 ppm, 3.76-4.02 ppm, 4.04-4.02 ppm, 3.66-3.76 ppm, and 3.83-3.66 ppm. Then, to evaluate whether these signals co-varied therefore could originate from the same metabolite, we performed STOCSY on 1D NMR spectra of control and Asc-treated groups. It revealed strong statistical correlations overlapping with the spin system-related correlations of 2D TOCSY spectra of the Asctreated group (Fig. 4A). The interrogation of the $B R M B$ database ( $\underline{w w w . b r m b . w i s c . e d u})$ Figure 4 revealed that the co-variating unknown signals corresponded to gluconic acid (Gna) (Fig. 4B). Especially, we verified that the aforementioned signals did not match those of phosphogluconolactone or phosphogluconate (PGna), two classical metabolites. The interrogation of the KEGG database (www.genome.ad.jp/kegg/kegg2.html) and the MetaCyc database (www.metacyc.org) localized Gna in human cell metabolic pathways, as a product of glucose dehydrogenation. To the best of our knowledge, this is the first time that Gna is found at rather high concentration levels in human tumor cells responding to an anticancer agent.

\subsection{Quantitative metabolite profiling of MCF7 cells response to MNPs}


Variations of 33 quantified metabolites were calculated using the technique of $2 \mathrm{D}{ }^{1} \mathrm{H}$ NMR spectroscopy-based metabolic profiling (Table 2). Data obtained at $6 \mathrm{~h}(\mathrm{n}=4)$ and $24 \mathrm{~h}(\mathrm{n}=4)$ were pooled together to improve statistical analysis.

In response to Asc, 3 metabolites accumulated dramatically: PUF $(\times 4.45, P<0.05)$, Cit $(\times 17.18, P<0.001)$, and Gna $(\times 9.75, P<0.005)$. Adenosine phosphates $($ AXP) were decreased $(\times 0.27, P<0.05)$. Significant alterations occurred in Glu parent-metabolites with the increase of $\operatorname{Gln}(\times 2.49, P<0.05)$ and Ala $(\times 2.32, P<0.05)$, and a decrease of Asp $(\times 0.30$, $P=$ NS). Methionine (Met) metabolism and transsulfuration were altered with the decrease of homocysteine (Hcy, $\times 0.42, P=\mathrm{NS}$ ), hypotaurine (hTa, $\times 0.14, P<0.005)$, and Tau $(\times 0.69, P$ $<0.05)$, and a mild decrease of total glutathione (GSx, $\times 0.87, P=\mathrm{NS})$. The subset of other amino acids showed an increase of Gly $(\times 2.67, P<0.05)$ and lysine $($ Lys, $\times 1.90, P<0.05)$. Phospholipid metabolism was strongly modified with the increase of PE $(\times 2.37, P<0.05)$, choline (Cho, $\times 1.39, P<0.05$ ), cytidine diphosphocholine (CDPC, $\times 1.76, P<0.05)$, and phosphatidylcholine $(\mathrm{PtC}, \times 1.33, P=\mathrm{NS})$, and the decrease of GPE $(\times 0.64, P<0.05)$, glycerophosphocholine (GPC, $\times 0.44, P<0.01)$, and PC $(\times 0.86, P=\mathrm{NS})$.

In response to Lam-D, major metabolite variations were an increase of PUF $(\times 12.66, P<$ 0.05 , one-tailed test $), \operatorname{Asp}(\times 7.21, P<0.05$, one-tailed test $)$ and Glu $(\times 14.73, P<0.05)$. Other changes included the increase of Lac $(\times 2.26, P<0.05)$ and Ace $(\times 9.56, P=$ NS $)$. Myoinositol (MyI) was significantly increased $(\times 2.68, P<0.05)$. The other amino acid subset showed an increase of Ala $(\times 3.94, P<0.01)$, Gly $(\times 2.75, P<0.05$, one-tailed test $)$, and Lys $(\times 2.58, P<$ 0.05). Phospholipid metabolism was modified with an increase in CDPC $(\times 2.22, P<0.01)$, and a moderate decrease of $\mathrm{PtC}(\times 0.69, P=\mathrm{NS})$.

Exposure to KF led to a large increase in PUF $(\times 9.76, P<0.05)$ and $\mathrm{tFA}(\times 4.17, P<0.05)$. Phospholipid metabolism was modified, with a decrease in $\mathrm{PC}(\times 0.56, P<0.05)$, GPE $(\times 0.65$, $P<0.01)$, and GPC $(\times 0.58, P=\mathrm{NS})$. N-acetylaspartate $(\mathrm{NAA})$ decreased $(\times 0.59, P<0.05)$, 
and Ace and Asp increased $(\times 2.28, P=\mathrm{NS}$, and $\times 2.78, P<0.05$, respectively). The Transsulfuration subset included the decrease of Hcy $(\times 0.55, P=\mathrm{NS}), \mathrm{hTa}(\times 0.45, P=\mathrm{NS})$, and GSx $(\times 0.76, P<0.05)$. In addition Gly was increased $(\times 1.51, P<0.05)$.

To assist the biochemical interpretation of the response to Asc, an unsupervised statistical description of data was performed using hierarchical clustering. The analysis clearly separated treated from untreated cells (Fig. 5). Three major clusters were obtained. A first cluster containing Cit and Gna also included Ala, Gln, Lys, Cho, tFA, PE, PUF, CDPC, and PtC. It showed a close co-variation between Cit and Gna levels, and between these metabolites and phospholipid derivatives. A second cluster (NAA, AXP, total creatine (tCr), Tau, hTa, GPC, GPE, Ace, Hcy, proline (Pro), Asp, and MyI) showed a co-variation between metabolites associated to acetyl-CoA metabolism and bioenergetics (NAA, AXP, tCr, and Ace), also between metabolites of transsulfuration and transmethylation (tCr, Tau, hTa, and Hcy). A third cluster showed a correlation between Lac, PC and GSx. An interpretation of biochemical disorders is proposed in Fig. 6 for Asc, Lam-D and KF.

\section{Discussion}

Metabolomics allows for a global assessment of a cellular state, integrating genetic regulation, activity of enzymes, and cellular environment [27, 28]. Compared with genomics or proteomics, metabolomics probably more closely reflects phenotype. There is growing evidence that metabolomics may provide novel insights into the mechanism of action of chemotherapy agents, and help identify metabolic pathways and enzyme targets for these agents [3-5]. The present study exploited new developments in HRMAS proton NMR spectroscopy-based metabolomics to help unravel the mechanism of the response of MCF7 cells to MNPs. The major metabolic findings of this study are the identification of the response of MCF7 cells to Asc involving enzyme blockade in citrate metabolism, 
mitochondrial-cytosolic carrier disorders in response to Lam-D, and increased lipid membrane catabolism in response to KF.

Asc, a marine topoisomerase II inhibitor, induces outer and inner mitochondrial membrane permeabilization through cytochrome $c$ release from mitochondria into the cytosol, and loss of MTP [7]. Asc may also cleave DNA by ROS generation [9]. Although chemical and molecular biology of ROS, and cellular redox regulation have deserved extensive work, knowledge is very partial yet on biochemical disorders induced by oxidative stress. We found the accumulation of Cit, primarily a product of the TCA cycle, in cells treated by Asc. This finding may be explained by enzyme blockade at the 3 levels of citrate processing: mitochondrial aconitase 2 (Aco2), cytosolic aconitase 1 (Aco1), 2 isozymes (E.C.4.2.1.3) which catalyze dehydrogenation of Cit into isocitrate, and ACL, the first committed step in cholesterol and de novo fatty acid synthesis. It has been shown that superoxide specifically reacts with $4 \mathrm{Fe}-4 \mathrm{~S}$ centers present in mitochondrial complexes I and II, Aco1 and Aco2 [29]. Aconitases can be rapidly inactivated by ROS [30]. It was reported that Cit levels increased in response to $\mathrm{H}_{2} \mathrm{O}_{2}$ suggesting the inhibition of Aco2 [30]. Accumulation of Cit was also observed in vivo in chronic cardiomyopathy induced by doxorubicin, a topoisomerase II inhibitor [31]. We identified a specific response to Asc involving the accumulation of Gna. The presence of Gna was already reported in fibroblasts transfected by "cancer-causing genes" (telomerase catalytic subunit in combination with simian virus 40 large $\mathrm{T}$ antigen, small $\mathrm{T}$ antigen, and an oncogenic allele of H-ras) [32], but not at an as high level as that found in our study. Gna is a product of glucose dehydrogenation, and does not undergo further metabolism in human cells according to the $K E G G$ metabolic network database. Therefore when Gna was produced, it accumulated. Another glucose metabolizing pathway involves ALR2, which catalyzes the reduction of the aldehyde form of glucose into sorbitol with concomitant conversion of NADPH to NADP+. ALR2 inhibition was reported in vitro 
for heterocyclic compounds isolated from marine tunicates [14]. The phosphorylated form of Gna, PGna, is a well-known intermediate of the pentose-phosphate pathway which plays a major role in the adaptive response to oxidative stress by regenerating NADPH [33]. It does not accumulate since it is metabolized into nucleic acids or back into glycolysis intermediates. In contrast, glucose rerouting towards Gna biosynthesis requires the inhibition or saturation of enzyme activities immediately downstream glucose. This could result from either blockade or rate-limitation of glucose 6-phosphate dehydrogenase (G6PD, E.C.1.1.1.49) or hexokinase (HK, E.C.2.7.1.1). G6PD may be limitated in case of a major need for NADPH caused by ROS accumulation. Alternatively HK may be blocked, as supported by the high concentration of Cit accumulating in response to Asc, and the close co-variation between Cit and Gna levels shown by hierarchical clustering. In addition, blockade of mitochondrial membrane HK (HKII) may cause its detachment from mitochondrial voltage-dependent anion channel (VDAC), thus triggering loss of mitochondrial membrane potential and apoptosis [34]. Another finding of hierarchical clustering was the co-variation between Cit, Gna, and phospholipid derivatives (PE, tFA, PUF, CDPC, and PtC), in favour of phospholipid metabolism reprogramming following glycolysis downregulation probably through diacylglycerol limitation. Also the decrease of AXP, NAA, Lac, and Ace levels suggested the deficiency of bioenergetics pathways.

Lam-D, a pyrrole alkaloid, is considered as a bisfunctional pharmacologic effector agent. It triggers apoptosis and MPT, through either an indirect effect following topoisomerase I inhibition or a direct action on mitochondria [11]. Lam-D has no effect on mitochondrial ROS production in cancer cells as previously reported [35], meaning that aconitases are not affected by ROS, as confirmed by the low level of Cit in our study. MPT triggered by Lam-D may lead to decreased mitochondrial membrane potential and decreased ATP production [36]. According to our findings, this could be related to the alteration of Glu-Asp mitochondrial- 
cytosolic transport. Cytosolic aspartate aminotransferase (AAT, E.C.2.6.1.1) and mitochondrial AAT function in tandem with malate dehydrogenase (MDH, E.C.1.1.1.37) to cycle the malate-aspartate shuttle (MAS). $\mathrm{Ca}^{2+}$ flux through mitochondrial membrane is a major regulator of the activity of MAS or Krebs cycle dehydrogenases which mostly exclude one another [37]. Lam-D has been shown to reduce the threshold of $\mathrm{Ca}^{2+}$ necessary for MPT induction which precedes inhibition of MAS, and triggers apoptosis in cancer cells $[11,36]$. Therefore, in our study, Glu and Asp accumulated probably as a consequence of MAS inhibition. Moreover, the downregulation of the NADH shuttle associated to MAS probably activated cytosolic NADH-consuming pathways [38] which could explain the increase in Lac and $\mathrm{EtOH}$ found in this study.

$\mathrm{KF}$, a small natural peptide, was reported to significantly downregulate erbB3 protein expression in KF-sensitive, high ErbB3-expressing breast carcinoma SKBR3 cells, and to efficiently inhibit the phosphatidylinositol 3-kinase/Akt signaling pathway in these cells [39]. This agent also provokes membrane disorders, and induction of oncosis through lysosomal membrane depolarization [40]. In this study, we observed cell swelling and fatty acid accumulation in KF-treated MCF7 cells. Fatty acids could be released from membranes in phagosomes through the activity of lysosomal lipases. KF could induce mitochondrial autophagy as reported in PC3 prostate cells [17]. In our study, membrane disorders could be linked to other biochemical alterations including decrease in NAA, a precursor for membrane lipid synthesis through the supply of acetyl-CoA [41].

In conclusion, the major metabolic findings of this HRMAS proton NMR spectroscopy-based metabolomics investigation in MCF7 breast cancer cells are the identification of enzyme blockade in citrate metabolism in response to Asc, mitochondrial-cytosolic carrier disorders in response to Lam-D, and increased lipid membrane catabolism in response to KF. This in vitro 
metabolomics study provides metabolic endpoints of the response of breast cancer cells to MNPs, also potential targets for these agents. These findings may serve the design of MNPevaluating clinical trials in breast cancer.

\section{Acknowledgements}

The authors thank Dr Anne Cayre for microscopy analysis. This work was supported by La Ligue Régionale Contre le Cancer (Comités du Cantal et du Puy de Dôme).

\section{References}

[1] Simmons TL, Andrianasolo E, McPhail K, Flatt P, Gerwick WH. Marine natural products as anticancer drugs. Mol Cancer Ther 2005;4:333-42.

[2] Banerjee S, Wang Z, Mohammad M, Sarkar FH, Mohammad RM. Efficacy of selected natural products as therapeutic agents against cancer. J Nat Prod 2008;71:492-6.

[3] Chung YL, Griffiths JR. Using metabolomics to monitor anticancer drugs. Ernst Schering Found Symp Proc 2007:55-78.

[4] Bayet-Robert M, Morvan D, Chollet P, Barthomeuf C. Pharmacometabolomics of docetaxel-treated human MCF7 breast cancer cells provides evidence of varying cellular responses at high and low doses. Breast Cancer Res Treat 120:613-26.

[5] Morvan D, Demidem A, Guenin S, Madelmont JC. Methionine-dependence phenotype of tumors: metabolite profiling in a melanoma model using L-[methyl-13C]methionine and high-resolution magic angle spinning $1 \mathrm{H}-13 \mathrm{C}$ nuclear magnetic resonance spectroscopy. Magn Reson Med 2006;55:984-96.

[6] Bayet-Robert M, Loiseau D, Rio P, Demidem A, Barthomeuf C, Stepien G, et al. Quantitative two-dimensional HRMAS 1H-NMR spectroscopy-based metabolite 
profiling of human cancer cell lines and response to chemotherapy. Magn Reson Med 2010;63:1172-83.

[7] Dirsch VM, Kirschke SO, Estermeier M, Steffan B, Vollmar AM. Apoptosis signaling triggered by the marine alkaloid ascididemin is routed via caspase- 2 and JNK to mitochondria. Oncogene 2004;23:1586-93.

[8] Dassonneville L, Wattez N, Baldeyrou B, Mahieu C, Lansiaux A, Banaigs B, et al. Inhibition of topoisomerase II by the marine alkaloid ascididemin and induction of apoptosis in leukemia cells. Biochem Pharmacol 2000;60:527-37.

[9] Matsumoto SS, Biggs J, Copp BR, Holden JA, Barrows LR. Mechanism of ascididemin-induced cytotoxicity. Chem Res Toxicol 2003;16:113-22.

[10] Tamm C, Zhivotovsky B, Ceccatelli S. Caspase-2 activation in neural stem cells undergoing oxidative stress-induced apoptosis. Apoptosis 2008;13:354-63.

[11] Kluza J, Gallego MA, Loyens A, Beauvillain JC, Sousa-Faro JM, Cuevas C, et al. Cancer cell mitochondria are direct proapoptotic targets for the marine antitumor drug lamellarin D. Cancer Res 2006;66:3177-87.

[12] Baunbaek D, Trinkler N, Ferandin Y, Lozach O, Ploypradith P, Rucirawat S, et al. Anticancer alkaloid lamellarins inhibit protein kinases. Mar Drugs 2008;6:514-27.

[13] Fan H, Peng J, Hamann MT, Hu JF. Lamellarins and related pyrrole-derived alkaloids from marine organisms. Chem Rev 2008;108:264-87.

[14] Manzanaro S, Salva J, de la Fuente JA. Phenolic marine natural products as aldose reductase inhibitors. J Nat Prod 2006;69:1485-7.

[15] Sewell JM, Mayer I, Langdon SP, Smyth JF, Jodrell DI, Guichard SM. The mechanism of action of Kahalalide F: variable cell permeability in human hepatoma cell lines. Eur J Cancer 2005;41:1637-44. 
[16] Garcia-Rocha M, Bonay P, Avila J. The antitumoral compound Kahalalide F acts on cell lysosomes. Cancer Lett 1996;99:43-50.

[17] Suarez Y, Gonzalez L, Cuadrado A, Berciano M, Lafarga M, Munoz A. Kahalalide F, a new marine-derived compound, induces oncosis in human prostate and breast cancer cells. Mol Cancer Ther 2003;2:863-72.

[18] Rademaker-Lakhai JM, Horenblas S, Meinhardt W, Stokvis E, de Reijke TM, Jimeno JM, et al. Phase I clinical and pharmacokinetic study of kahalalide F in patients with advanced androgen refractory prostate cancer. Clin Cancer Res 2005;11:1854-62.

[19] Martin-Algarra S, Espinosa E, Rubio J, Lopez Lopez JJ, Manzano JL, Carrion LA, et al. Phase II study of weekly Kahalalide F in patients with advanced malignant melanoma. Eur J Cancer 2009;45:732-5.

[20] Ballot C, Kluza J, Martoriati A, Nyman U, Formstecher P, Joseph B, et al. Essential role of mitochondria in apoptosis of cancer cells induced by the marine alkaloid Lamellarin D. Mol Cancer Ther 2009;8:3307-17.

[21] Rago R, Mitchen J, Wilding G. DNA fluorometric assay in 96-well tissue culture plates using Hoechst 33258 after cell lysis by freezing in distilled water. Anal Biochem 1990;191:31-4.

[22] Morvan D, Demidem A, Papon J, De Latour M, Madelmont JC. Melanoma tumors acquire a new phospholipid metabolism phenotype under cystemustine as revealed by high-resolution magic angle spinning proton nuclear magnetic resonance spectroscopy of intact tumor samples. Cancer Res 2002;62:1890-7.

[23] Morvan D, Demidem A. Metabolomics by proton nuclear magnetic resonance spectroscopy of the response to chloroethylnitrosourea reveals drug efficacy and tumor adaptive metabolic pathways. Cancer Res 2007;67:2150-9. 
[24] Chong IG, Jun CH. Performance of some variable selection methods when multicollinearity is present. Chemometrics and Intelligent Laboratory Systems 2005;78:103-12.

[25] Holmes E, Cloarec O, Nicholson JK. Probing latent biomarker signatures and in vivo pathway activity in experimental disease states via statistical total correlation spectroscopy (STOCSY) of biofluids: application to $\mathrm{HgCl} 2$ toxicity. J Proteome Res 2006;5:1313-20.

[26] Page RD. TreeView: an application to display phylogenetic trees on personal computers. Comput Appl Biosci 1996;12:357-8.

[27] Griffin JL, Shockcor JP. Metabolic profiles of cancer cells. Nat Rev Cancer $2004 ; 4: 551-61$.

[28] Mendes P, Kell DB, Westerhoff HV. Why and when channelling can decrease pool size at constant net flux in a simple dynamic channel. Biochim Biophys Acta 1996;1289:175-86.

[29] Hausladen A, Fridovich I. Superoxide and peroxynitrite inactivate aconitases, but nitric oxide does not. J Biol Chem 1994;269:29405-8.

[30] Katoh I, Sato S, Fukunishi N, Yoshida H, Imai T, Kurata S. Apaf-1-deficient fog mouse cell apoptosis involves hypo-polarization of the mitochondrial inner membrane, ATP depletion and citrate accumulation. Cell Res 2008;18:1210-9.

[31] Lebrecht D, Setzer B, Ketelsen UP, Haberstroh J, Walker UA. Time-dependent and tissue-specific accumulation of mtDNA and respiratory chain defects in chronic doxorubicin cardiomyopathy. Circulation 2003;108:2423-9.

[32] Ramanathan A, Wang C, Schreiber SL. Perturbational profiling of a cell-line model of tumorigenesis by using metabolic measurements. Proc Natl Acad Sci U S A 2005;102:5992-7. 
[33] Salvemini F, Franze A, Iervolino A, Filosa S, Salzano S, Ursini MV. Enhanced glutathione levels and oxidoresistance mediated by increased glucose-6-phosphate dehydrogenase expression. J Biol Chem 1999;274:2750-7.

[34] Machida K, Ohta Y, Osada H. Suppression of apoptosis by cyclophilin D via stabilization of hexokinase II mitochondrial binding in cancer cells. J Biol Chem 2006;281:14314-20.

[35] Gallego MA, Ballot C, Kluza J, Hajji N, Martoriati A, Castera L, et al. Overcoming chemoresistance of non-small cell lung carcinoma through restoration of an AIFdependent apoptotic pathway. Oncogene 2008;27:1981-92.

[36] Ballot C, Kluza J, Lancel S, Martoriati A, Hassoun SM, Mortier L, et al. Inhibition of mitochondrial respiration mediates apoptosis induced by the anti-tumoral alkaloid lamellarin D. Apoptosis Published on line 12 February 2010.

[37] Contreras L, Satrustegui J. Calcium signaling in brain mitochondria: interplay of malate aspartate NADH shuttle and calcium uniporter/mitochondrial dehydrogenase pathways. J Biol Chem 2009;284:7091-9.

[38] Satrustegui J, Pardo B, Del Arco A. Mitochondrial transporters as novel targets for intracellular calcium signaling. Physiol Rev 2007;87:29-67.

[39] Janmaat ML, Rodriguez JA, Jimeno J, Kruyt FA, Giaccone G. Kahalalide F induces necrosis-like cell death that involves depletion of ErbB3 and inhibition of Akt signaling. Mol Pharmacol 2005;68:502-10.

[40] Barthomeuf C, Morvan D, Lim S, Chollet P, Alberico F, Cuvillier O. Metabolomic analysis of human MCF7 breast carcinoma cells by 1H-NMR identify phospholipid metabolism as an important target of kahalalide $\mathrm{F}$ and myoinositol as a drug-response biomarker. Proceedings of the American Association for Cancer Research, 2008. p. 3944. 
[41] Mehta V, Namboodiri MA. N-acetylaspartate as an acetyl source in the nervous system. Brain Res Mol Brain Res 1995;31:151-7. 


\section{Figure Legends}

Fig.1 - Global cytotoxicity response of MCF7 cells to MNPs. Cells were exposed to the vehicle (CT, 0.5\% DMSO) or ascididemin (Asc, $5 \mu \mathrm{M})$, lamellarin-D (Lam-D, $5 \mu \mathrm{M}$ ), and kahalalide F (KF, $3 \mu \mathrm{M})$ for 4, 6, 8, 24, and 48 h. (A) Cellular DNA content (\% of CT) as an index of cell proliferation and cytotoxicity in attached cells was evaluated using the fluorescence intensity of Hoechst 33342 dye after a 6 h-, 24 h- and 48 h-treatment to Asc, Lam-D or KF. (B) Apoptosis was determined by FACS after cell staining with propidium iodide. The percentage of apoptotic cells was quantified as the amount of cells in sub-G1 phase after exposure to Asc, Lam-D or KF for 4, 6, and 24 h. ${ }^{*} P<0.05$, and $* * P<0.01$ (Mann Whitney test, treated vs. CT cells). (C) Nuclear morphology of attached MCF7 cells was assessed under fluorescence microscopy (magnification 60×), using Hoechst 33342 staining, after $4 \mathrm{~h}, 6 \mathrm{~h}$ and $24 \mathrm{~h}$ exposure to CT, Asc, Lam-D or KF. Arrows indicate apoptotic bodies.

Fig.2- Typical 1D proton NMR spectra of the response to MNPs. Acquisition of 1D HRMAS ${ }^{1} \mathrm{H}-\mathrm{NMR}$ spectra was done at $4 \mathrm{~h}$ (top), $6 \mathrm{~h}$ (middle), and $24 \mathrm{~h}$ (bottom) in CT untreated, Asc-, Lam-D-, and KF-treated MCF7 cells. Abbreviations, as in text.*, fatty acid signals.

Fig.3- PLS-DA reveals discriminating NMR spectrum signals. Spectral regions between 4.3 and $1.1 \mathrm{ppm}$ were binned in $0.012 \mathrm{ppm}$ rectangular buckets, and processed by PLS-DA. The number of samples for the CT group was $n=8$ compared with $n=8$ (Asc, top), $n=4$ (Lam$\mathrm{D}$, middle), and $\mathrm{n}=4$ (KF, bottom). VIP, variable importance in the projection. The VIP value was chosen to provide between 10 to 15 discriminating signals (VIP=1.2 for Asc, and 1.5 for 
Lam-D and KF). Abbreviations, as in text. EtOH, ethanol $\left(\mathrm{CH}_{2}\right.$ signal at $3.65 \mathrm{ppm}$ and $\mathrm{CH}_{3}$ signal at $1.18 \mathrm{ppm}) . \mathrm{X}_{1}$ to $\mathrm{X}_{5}, 5$ unknown signals.

Fig.4- Identification of gluconic acid (Gna). (A) Top left, typical 2D TOCSY spectrum selection in the 3.55-4.20 $\times 3.55-4.20 \mathrm{ppm}$ area, with the corresponding $1 \mathrm{D}$ NMR spectrum above, in the Asc-treated group; top right, typical 2D TOCSY spectrum in the CT group; bottom left, Gna spectrum from the BRMB database (www.brmb.wisc.edu); bottom right, STOCSY spectrum obtained from the Asc and CT sets of 1D NMR spectra (Asc, $n=8$ and CT, $\mathrm{n}=8$ ). Attribution of signals is given in reference to Fig. 4B. (B) Chemical structure of Gna.

Fig.5 COLOR- Metabolite clustering applied to the response to Asc. Hierarchical clustering of individuals and metabolites shows clear separation between untreated control (CT) and Asc-treated (Asc) cell cultures. The metabolite-associated dendrogram is represented, and identified co-variations between sets of metabolites. Red, metabolite variations between average and average $+3 \times \mathrm{SD}$; green, metabolite variations between average and average $-3 \times \mathrm{SD}$.

Fig.5 GreyScale- Metabolite clustering applied to the response to Asc. Hierarchical clustering of individuals and metabolites shows clear separation between untreated control (CT) and Asc-treated (Asc) cell cultures. The metabolite-associated dendrogram is represented, and identified co-variations between sets of metabolites. Light grey, metabolite variations between average and average $+3 \times \mathrm{SD}$; dark grey, metabolite variations between average and average $-3 \times \mathrm{SD}$. 
Fig.6- Interpretative scheme of the response to MNPs. A summary of metabolic findings in MCF7 breast cancer cells, and their integration with literature data is given for the studied MNPs (main diagram, Asc and Lam-D; upper right inset, KF).

Metabolite abbreviations: ACoA, acetyl-CoA; $\underline{\text { Ala, }}$ alanine; $\underline{\text { Asp }}$, aspartate; $\underline{\text { Cit, }}$ citrate; $\underline{\text { FA, }}$ fatty acids; F6P, fructose 6-phosphate; Gna, gluconate; Glc, glucose; G6P, glucose 6-

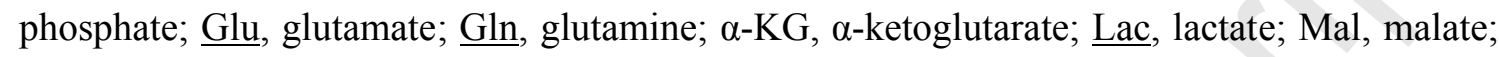
MAS, malate-aspartate shuttle; OAA, oxaloacetic acid; PGna, 6-phospho-gluconate; PUF, polyunsaturated fatty acids; ROS, reactive oxygen species. Enzyme abbreviations (italicized): Aco1; aconitase1 (cytosolic); Aco2, aconitase2 (mitochondrial); ALR2, aldose reductase; ACL, ATP-citrate lyase; G1D, glucose 1-dehydrogenase; GDH; glutamate dehydrogenase; HKI, hexokinase I; HKII, hexokinase II; PFK, phosphofructokinase. $\vdash$, enzyme inhibition; $\uparrow$, arrest of metabolism due to the lack of expression of downstream enzymes. Measured metabolites are underlined; thick arrows, metabolite variation in response to Asc (black arrows), Lam-D (grey arrows), and KF. Numbers in brackets: literature references. 
Table 1. Proton chemical shift for identified and quantified metabolites.

\begin{tabular}{|c|c|c|c|}
\hline $\begin{array}{l}\text { Subset of } \\
\text { metabolites }\end{array}$ & Chemical shift (ppm) in D20 & Metabolite & Abbreviation \\
\hline \multirow{7}{*}{$\begin{array}{l}\text { Bioenergetics } \\
\text { derivatives/ } \\
\text { Lipids }\end{array}$} & 8.53 & Adenosine phosphates & AXP \\
\hline & $1.34 \times 4.11$ & Lactate & Lac \\
\hline & 1.92 & Acetate & Ace \\
\hline & $0.88 \times 1.33$ & Total fatty acids & $\mathrm{tFA}$ \\
\hline & $2.79 \times 5.33$ & Polyunsaturated fatty acids & PUF \\
\hline & $2.55 \times 2.75$ & Citrate & Cit \\
\hline & $(3.54,3.61) \times 3.28$ & Myo-inositol & Myl \\
\hline \multirow{8}{*}{$\begin{array}{l}\text { Glutamate/ } \\
\text { Aspartate } \\
\text { derivatives }\end{array}$} & $2.06 \times 3.76$ & Glutamate & Glu \\
\hline & $2.12 \times 2.46$ & Glutamine & Gln \\
\hline & $2.03 \times 4.15$ & Proline & Pro \\
\hline & $1.47 \times 3.77$ & Alanine & Ala \\
\hline & $(2.88,2.95) \times 3.99$ & Asparagine & Asn \\
\hline & $(2.70,2.80) \times 3.89$ & Aspartate & Asp \\
\hline & $(2.50,2.70) \times 4.40$ & $\mathrm{~N}$-acetyl-aspartate & NAA \\
\hline & $(1.68,1.92) \times 3.23$ & Arginine & Arg \\
\hline \multirow{7}{*}{$\begin{array}{l}\text { Methionine/ } \\
\text { Transsulfuration } \\
\text { derivatives }\end{array}$} & $2.17 \times 2.63$ & Methionine & Met \\
\hline & $(1.72,2.13) \times 3.13$ & Polyamines & Ply \\
\hline & $2.17 \times 2.72$ & Homocysteine & Hcy \\
\hline & $3.035,3.93$ & Total creatine $=$ creatine + phosphocreatine & $\mathrm{tCr}$ \\
\hline & $(2.55,4.56) \times 2.17$ & Total glutathione $=\mathrm{GSH}+2 \times$ GSSG & GSx \\
\hline & $2.63 \times 3.35$ & Hypotaurine & $\mathrm{hTa}$ \\
\hline & $3.27 \times 3.43$ & Taurine & Tau \\
\hline \multirow{4}{*}{$\begin{array}{l}\text { Other amino } \\
\text { acids }\end{array}$} & 3.56 & Glycine & Gly \\
\hline & $1.90 \times 3.77$ & Lysine & Lys \\
\hline & $3.13 \times 3.99$ & Phenylalanine & Phe \\
\hline & $1.32 \times 3.58$ & Threonine & Thr \\
\hline \multirow{7}{*}{$\begin{array}{l}\text { Phospholidid } \\
\text { derivatives }\end{array}$} & $3.22 \times 3.99$ & Phosphoethanolamine & $\mathrm{PE}$ \\
\hline & $3.30 \times 4.12$ & Glycerophosphoethanolamine & GPE \\
\hline & $3.55 \times 4.07$ & Choline & Cho \\
\hline & $3.62 \times 4.18,3.22$ & Phosphocholine & $\mathrm{PC}$ \\
\hline & 3.26 & Phosphatidylcholine & $\mathrm{PtC}$ \\
\hline & $3.66 \times 4.42$ & Cytidine diphosphocholine & CDPC \\
\hline & $3.66 \times 4.34$ & Glycerophosphocholine & GPC \\
\hline
\end{tabular}


Table 2. Quantification of 33 metabolites in MCF7 tumor cells in response to marine natural products, using the technique of $2 \mathrm{D}{ }^{1} \mathrm{H}$ NMR spectroscopy-based metabolic profiling. Fold change in metabolite content in MCF7 cells exposed to $5 \mu \mathrm{M}$ ascididemin (Asc), $5 \mu \mathrm{M}$ lamellarin-D (Lam-D), and $3 \mu \mathrm{M}$ kahalalide $\mathrm{F}(\mathrm{KF})$ averaged over time (6 h and $24 \mathrm{~h}$ ). Significant changes are in bold. $P$-value was calculated using two-tailed Mann Whitney test. *One-tailed Mann Whitney test. Abbreviations, as in text. Parenthesis, SD. NC, not calculated.

\begin{tabular}{|c|c|c|c|c|c|c|}
\hline \multirow[b]{2}{*}{ Metabolite } & \multicolumn{2}{|c|}{ Asc $(5 \mu \mathrm{M})$} & \multicolumn{2}{|c|}{ Lam-D $(5 \mu \mathrm{M})$} & \multicolumn{2}{|c|}{$\mathrm{KF}(3 \mu \mathrm{M})$} \\
\hline & Fold change (SD) & $P$-value & Fold change (SD) & $P$-value & Fold change (SD) & $P$-value \\
\hline AXP & $0.27(0.87)$ & 0.015 & $0.36(0.72)$ & 0.1257 & $0.66(0.47)$ & 0.1264 \\
\hline tFA & $1.43(1.42)$ & 0.2476 & $6.67(6.52)$ & 0.3924 & $4.17(2.97)$ & 0.0412 \\
\hline PUF & $4.45(2.06)$ & 0.0154 & $12.66(11.60)$ & $0.0374^{*}$ & $9.76(5.54)$ & 0.0166 \\
\hline Lac & $0.80(0.83)$ & 0.5286 & $2.26(1.30)$ & 0.0415 & $1.63(1.49)$ & 0.2345 \\
\hline Cit & $17.18(4.67)$ & 0.0008 & $0.88(0.82)$ & 0.6104 & $1.31(1.21)$ & 0.7341 \\
\hline Ace & $\mathrm{NC}$ & - & $9.56(7.01)$ & 0.2345 & $2.28(1.95)$ & 0.2345 \\
\hline Myl & $0.94(0.76)$ & 0.6744 & $2.68(1.41)$ & 0.0108 & $0.35(0.86)$ & 0.1481 \\
\hline Gna & $9.75(3.19)$ & 0.0011 & $1.00(0.22)$ & 0.4892 & $1.28(1.59)$ & 0.6098 \\
\hline Glu & $1.58(1.49)$ & 0.5256 & $14.73(10.10)$ & 0.0107 & $1.10(1.93)$ & 0.4892 \\
\hline Gln & $2.49(1.59)$ & 0.0274 & $0.67(0.74)$ & 0.3082 & $1.62(1.30)$ & 0.0617 \\
\hline Pro & $0.52(0.78)$ & 0.3938 & $2.59(1.91)$ & 0.0613 & $1.19(1.19)$ & 0.3073 \\
\hline NAA & $0.74(0.88)$ & 0.2076 & $0.65(0.87)$ & 0.1742 & $0.59(0.92)$ & 0.0272 \\
\hline Ala & $2.32(1.50)$ & 0.0274 & $3.94(2.72)$ & 0.0066 & $1.07(1.17)$ & 0.7341 \\
\hline Asn & $0.73(0.85)$ & 0.2076 & $1.38(1.35)$ & 0.3082 & $1.03(1.16)$ & 0.7341 \\
\hline Asp & $0.30(0.83)$ & 0.1141 & $7.21(5.03)$ & $0.0415^{\star}$ & $2.78(0.96)$ & 0.0174 \\
\hline $\operatorname{Arg}$ & $0.88(0.87)$ & 0.4008 & $1.38(1.53)$ & 0.3082 & $0.73(0.80)$ & 0.2345 \\
\hline Ply & $1.58(1.21)$ & 0.0929 & $1.31(1.26)$ & 0.3958 & $1.47(1.35)$ & 0.4969 \\
\hline Hcy & $0.42(0.88)$ & 0.1141 & $0.58(0.79)$ & 0.4439 & $0.55(0.90)$ & 0.3958 \\
\hline $\mathrm{tCr}$ & $0.60(0.93)$ & 0.0274 & $0.68(0.79)$ & 0.3082 & $0.97(0.82)$ & 0.7341 \\
\hline $\mathrm{hTa}$ & $0.14(0.94)$ & 0.0011 & $0.33(0.84)$ & 0.0272 & $0.45(0.72)$ & 0.1264 \\
\hline Tau & $0.69(0.93)$ & 0.0117 & $0.82(0.77)$ & 0.3082 & $1.23(1.26)$ & 0.4969 \\
\hline GSx & $0.87(0.89)$ & 0.4622 & $0.75(0.82)$ & 0.1742 & $0.76(0.98)$ & 0.0415 \\
\hline Gly & $2.67(1.75)$ & 0.046 & $2.75(2.53)$ & $0.0374^{\star}$ & $1.51(1.17)$ & 0.0415 \\
\hline Lys & $1.90(1.22)$ & 0.0209 & $2.58(1.70)$ & 0.0415 & $0.70(0.81)$ & 0.3958 \\
\hline Phe & $1.10(1.12)$ & 0.3446 & $1.41(1.28)$ & 0.1742 & $0.84(0.96)$ & 0.8651 \\
\hline Thr & $0.94(0.78)$ & 0.7527 & $1.30(1.59)$ & 0.8651 & $0.57(0.74)$ & 0.2345 \\
\hline $\mathrm{PE}$ & $2.37(1.25)$ & 0.0117 & $1.25(1.29)$ & 0.2345 & $1.43(1.35)$ & 0.1264 \\
\hline GPE & $0.64(0.92)$ & 0.0117 & $0.87(0.78)$ & 0.8651 & $0.65(0.96)$ & 0.0066 \\
\hline Cho & $1.39(1.07)$ & 0.0117 & $0.96(0.91)$ & 0.8651 & $0.62(0.88)$ & 0.0617 \\
\hline $\mathrm{PC}$ & $0.86(0.90)$ & 0.5286 & $0.43(0.87)$ & 0.0415 & $0.56(0.95)$ & 0.0415 \\
\hline CDPC & $1.76(1.37)$ & 0.0209 & $2.22(1.27)$ & 0.0066 & $1.10(1.11)$ & 0.6104 \\
\hline $\mathrm{PtC}$ & $1.33(1.16)$ & 0.2076 & $0.69(0.83)$ & 0.0894 & $1.15(1.11)$ & 0.3082 \\
\hline GPC & $0.44(0.92)$ & 0.0087 & $0.88(0.71)$ & 0.0894 & $0.58(0.88)$ & 0.0894 \\
\hline
\end{tabular}


(A)

(B)

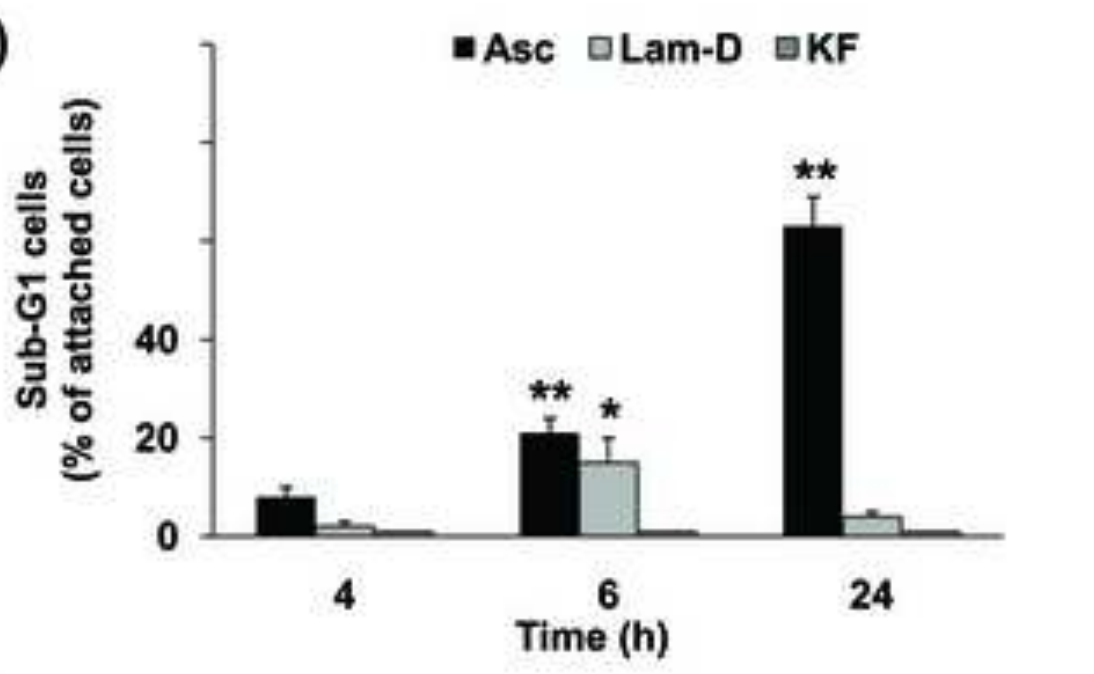

(C)
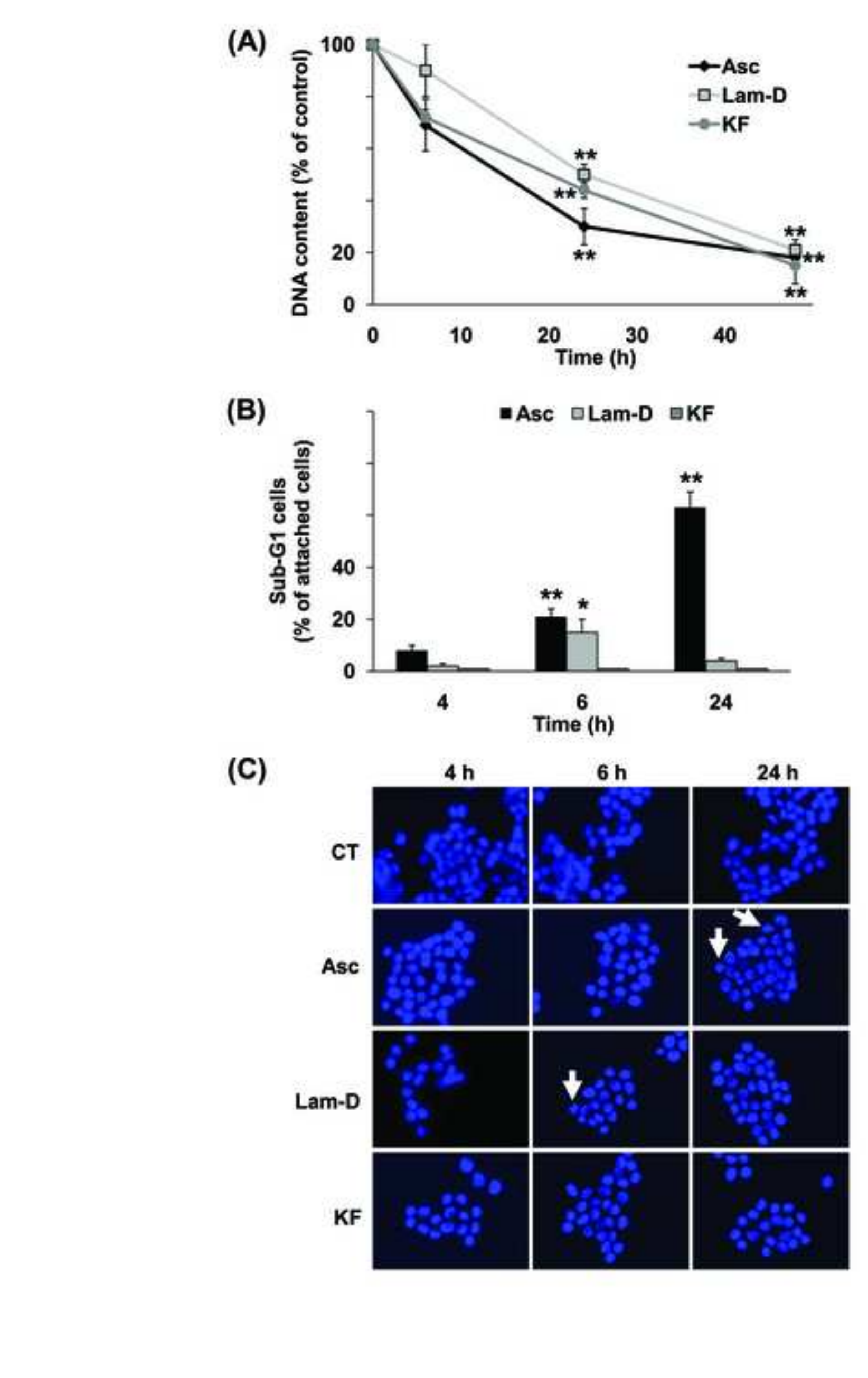

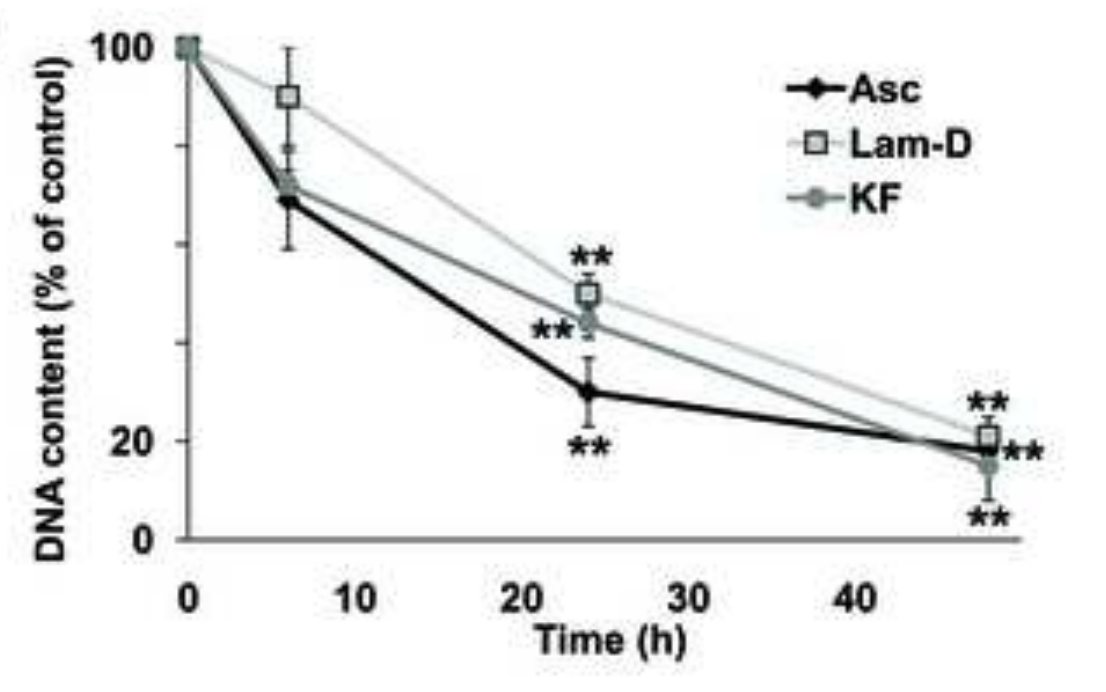

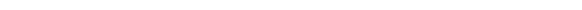
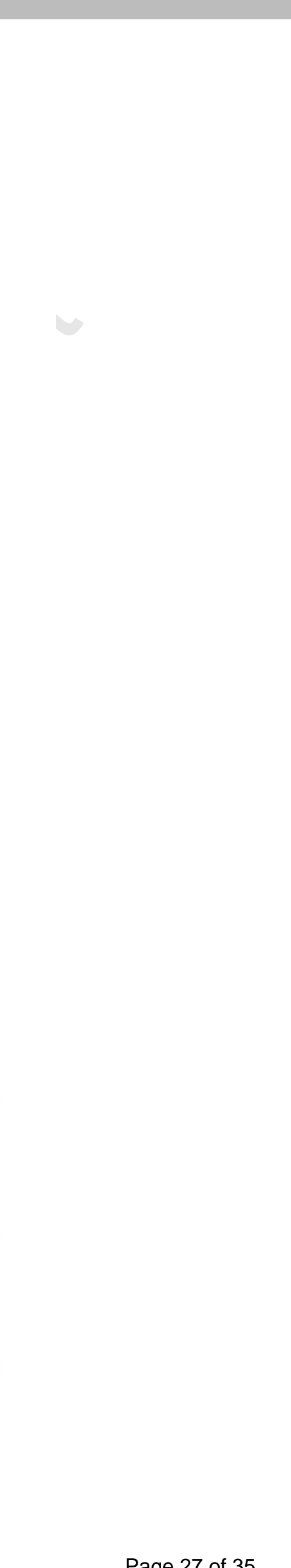

$-$


(A)

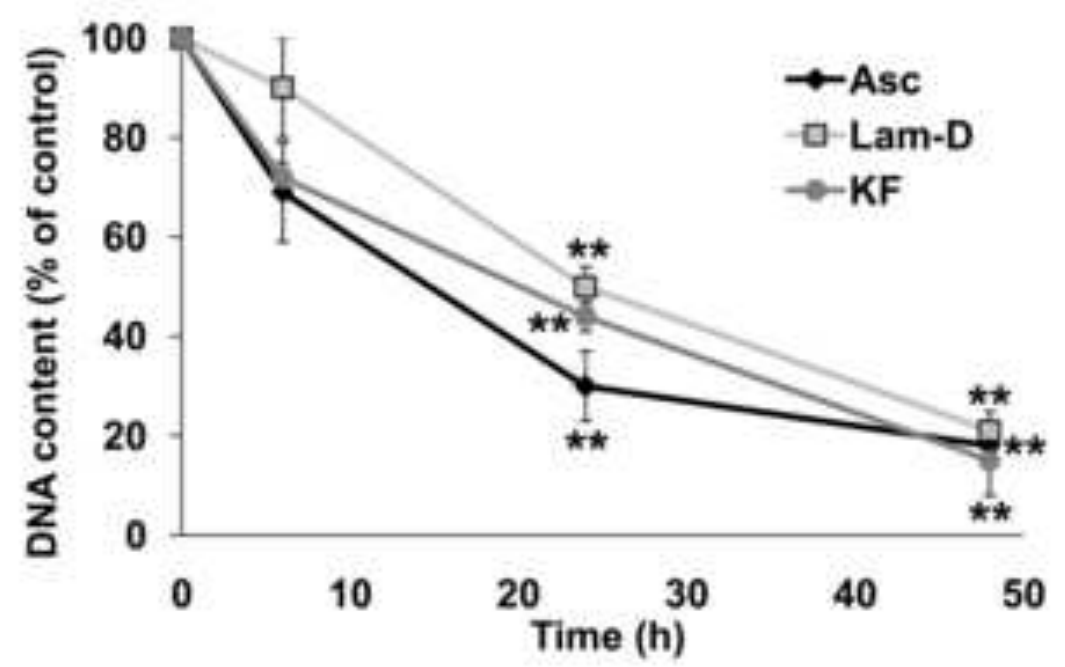

(B)

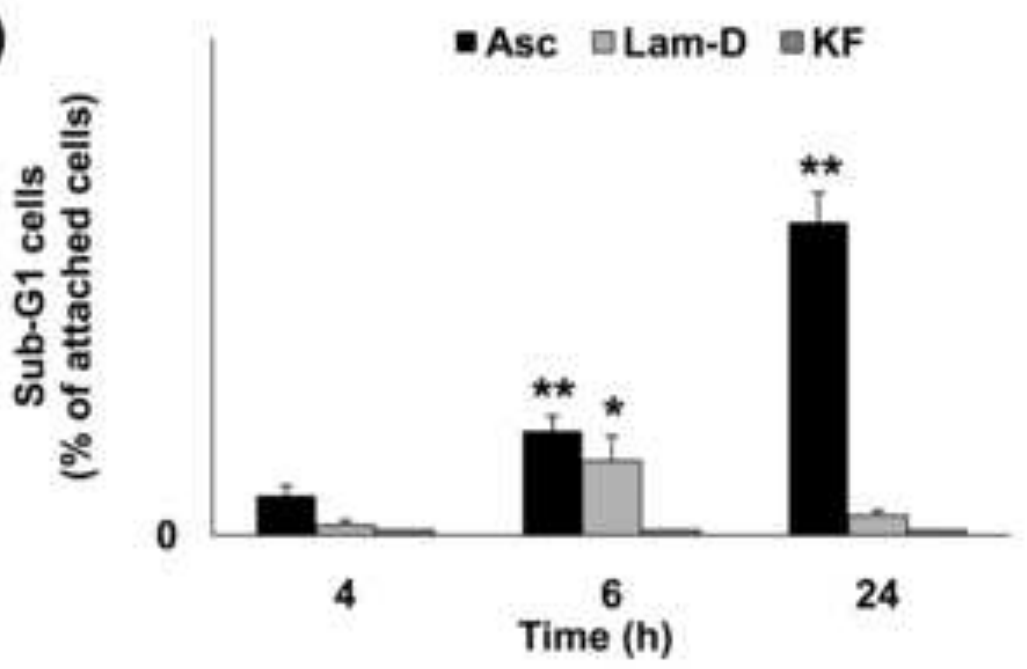

(C)

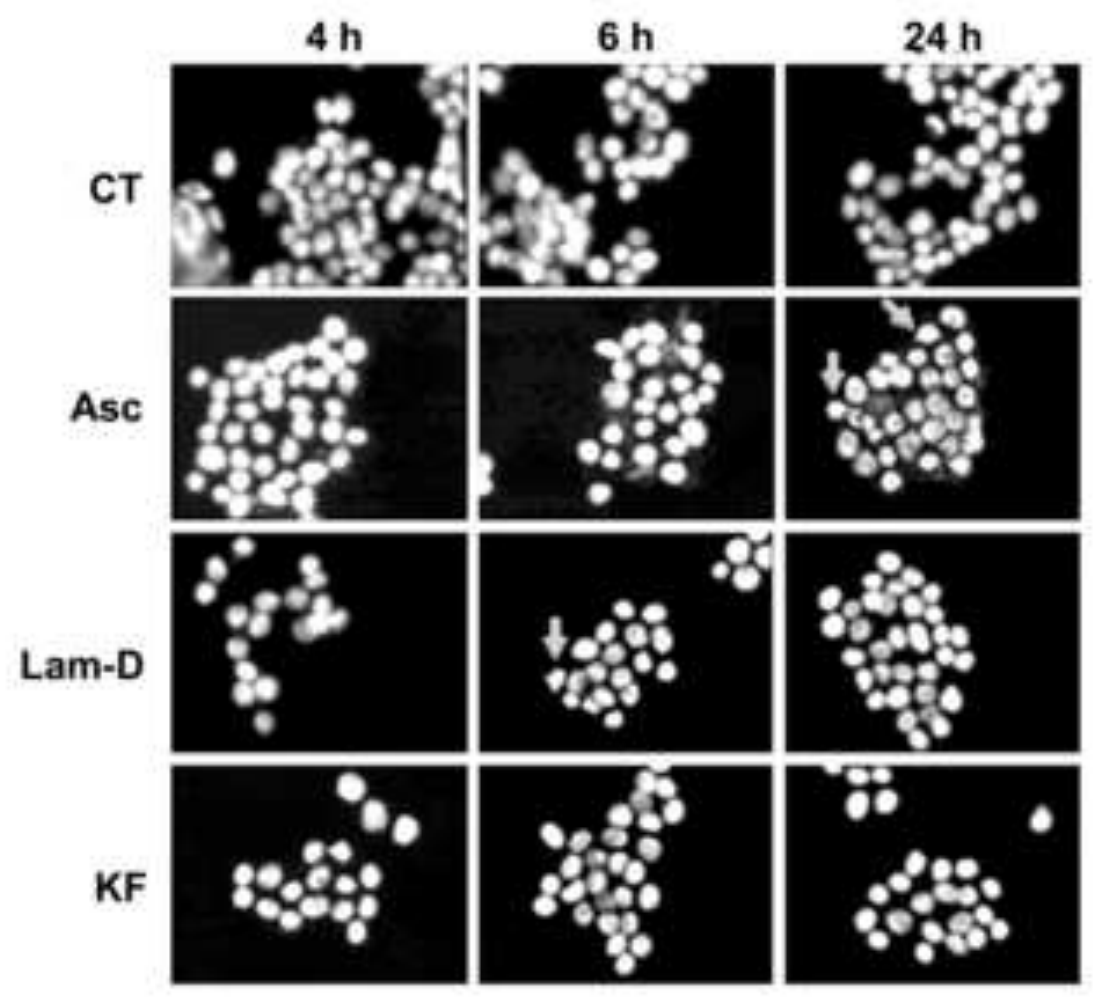



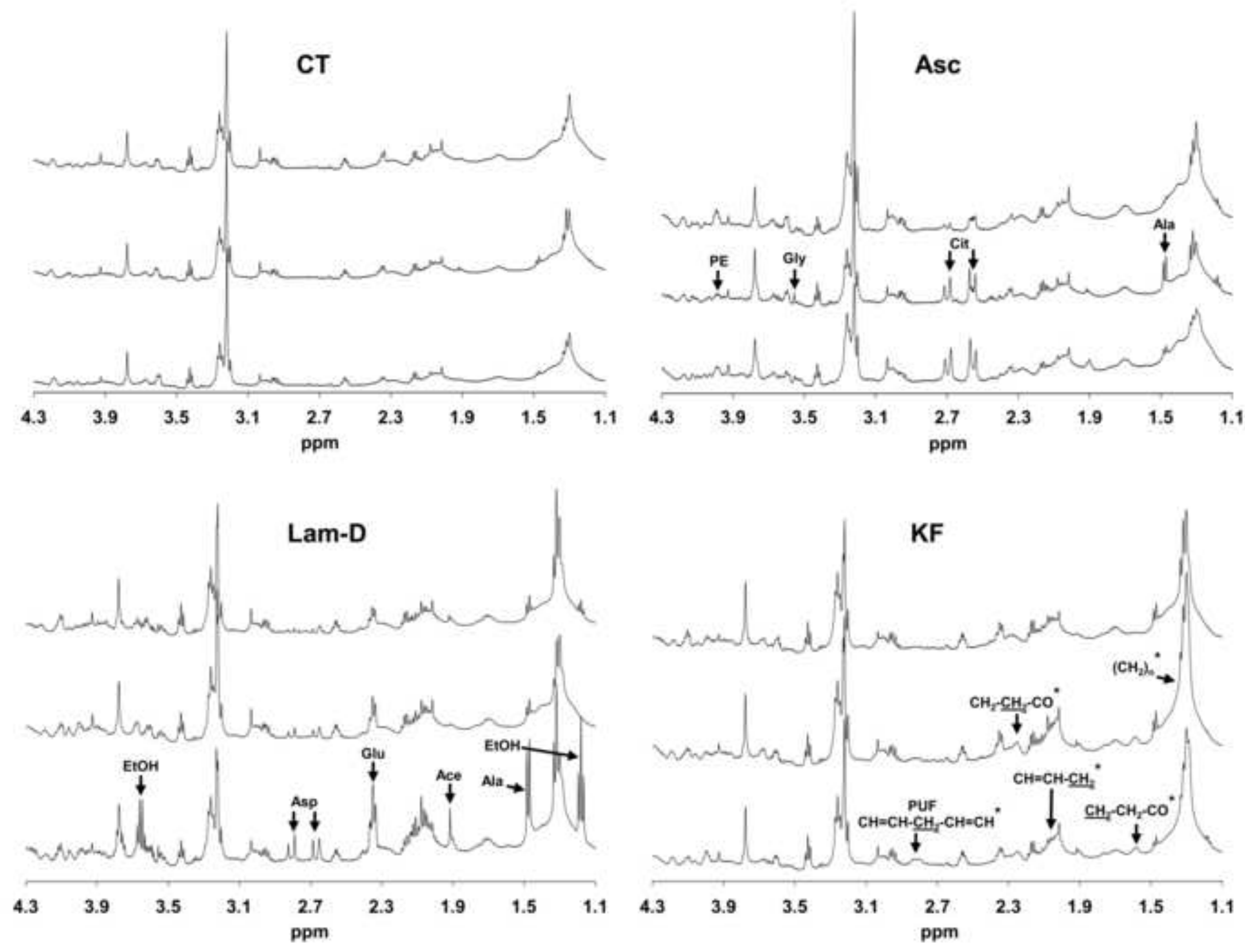

Page 29 of 35 


\section{Asc}

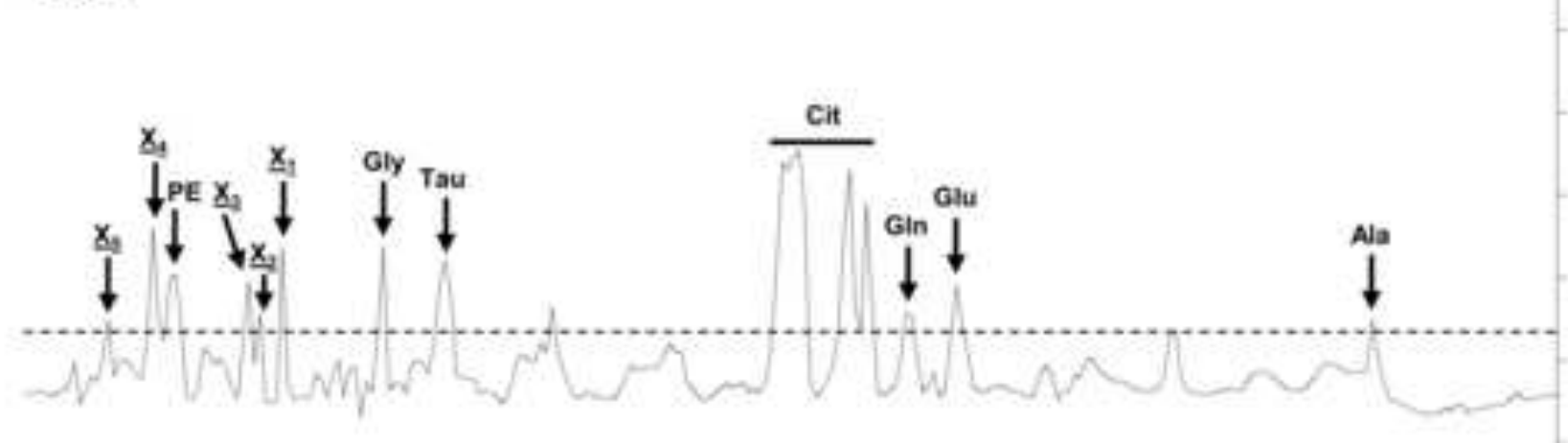

\section{$\begin{array}{lllllllllllllllll}4.3 & 4.1 & 3.9 & 3.7 & 3.5 & 3.3 & 3.1 & 2.9 & 2.7 & 2.5 & 2.3 & 2.1 & 1.9 & 1.7 & 1.5 & 1.3 & 1.1\end{array}$} ppm

\section{Lam-D}

\section{Asp}
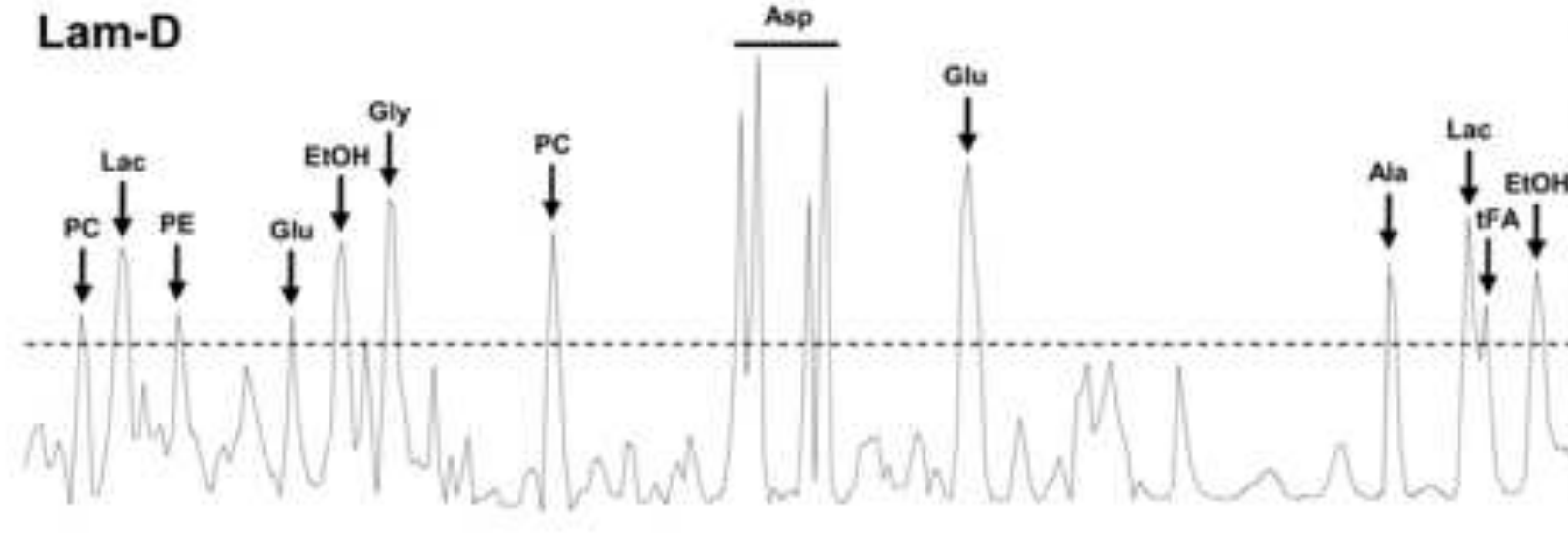

3.0

2.5

${ }_{1.5}^{2.0} \leqq$

1.0

0.5

0.0

\section{$\begin{array}{lllllllllllllllll}4.3 & 4.1 & 3.9 & 3.7 & 3.5 & 3.3 & 3.1 & 2.9 & 2.7 & 2.5 & 2.3 & 2.1 & 1.9 & 1.7 & 1.5 & 1.3 & 1.1\end{array}$} ppm

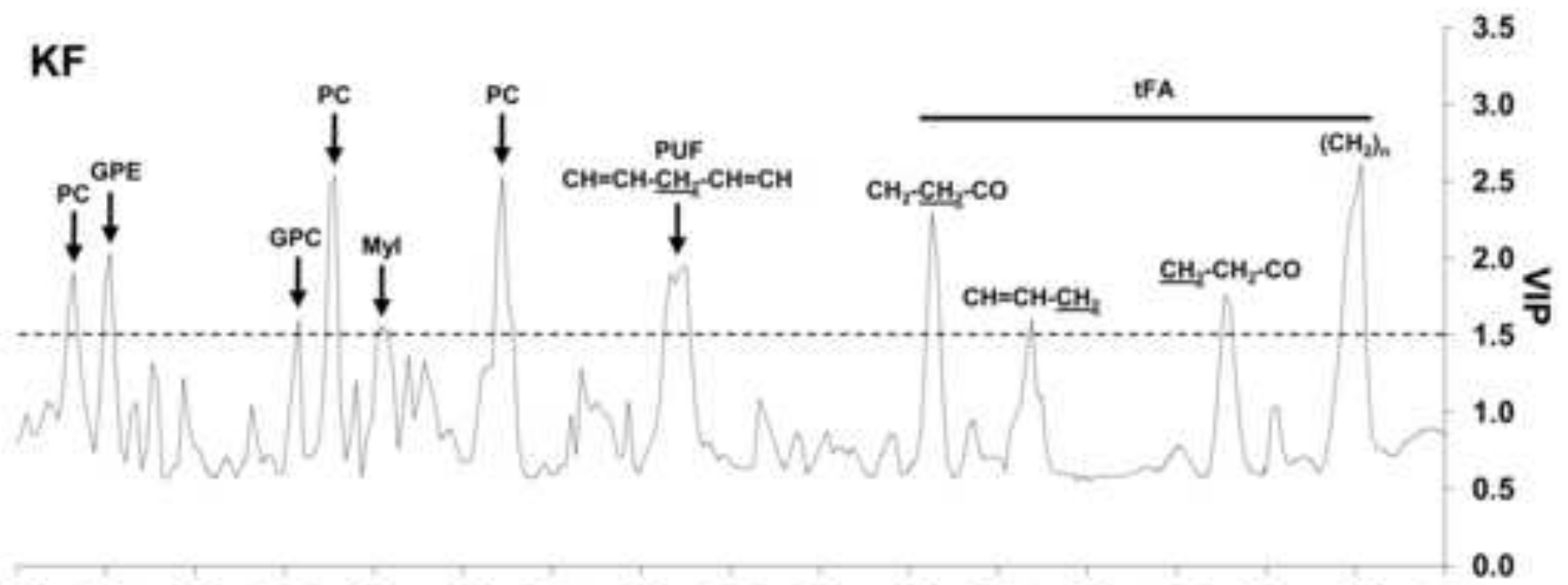

$\begin{array}{lllllllllllllllll}4.3 & 4.1 & 3.9 & 3.7 & 3.5 & 3.3 & 3.1 & 2.9 & 2.7 & 2.5 & 2.3 & 2.1 & 1.9 & 1.7 & 1.5 & 1.3 & 1.1\end{array}$ 
(A)
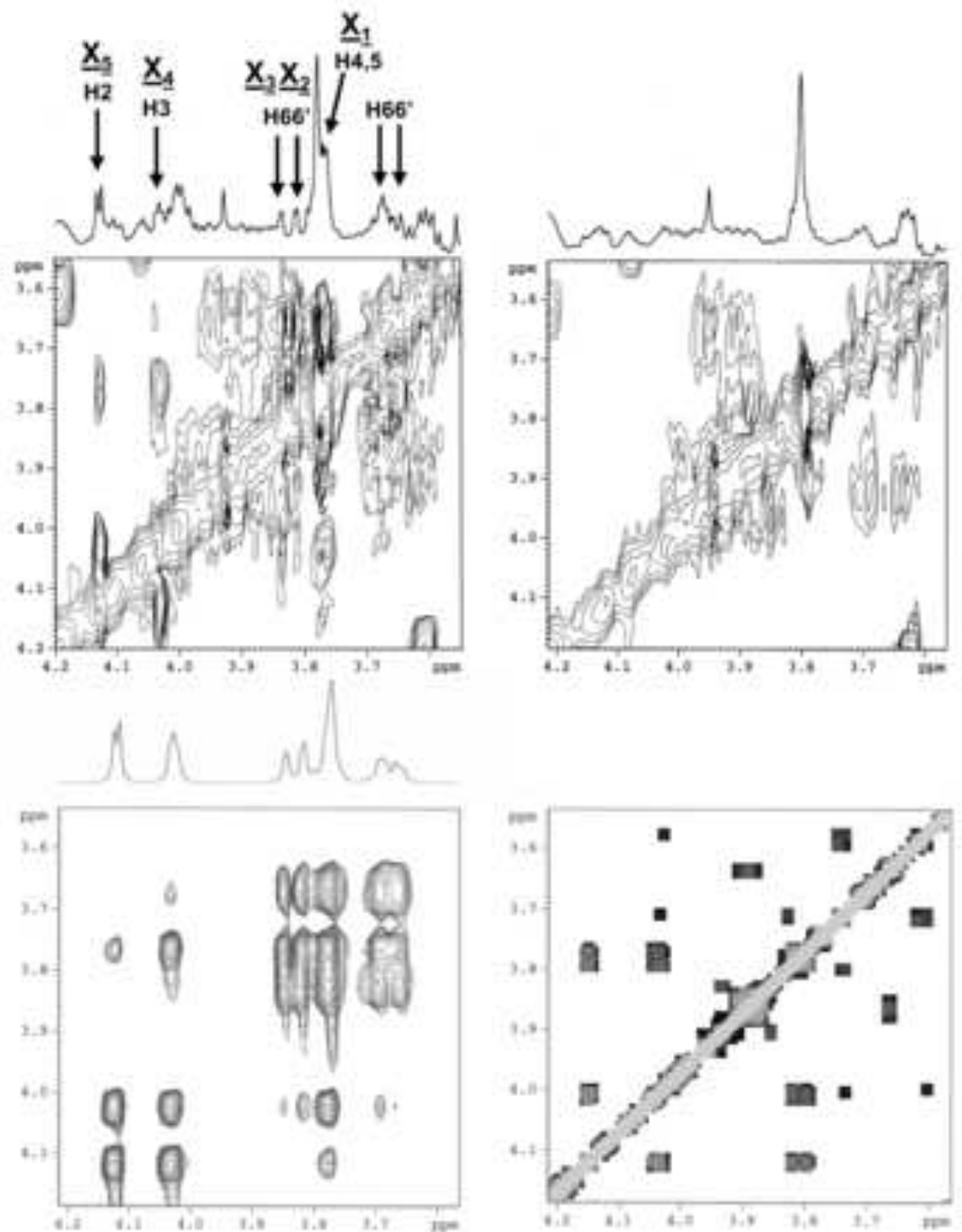

(B)

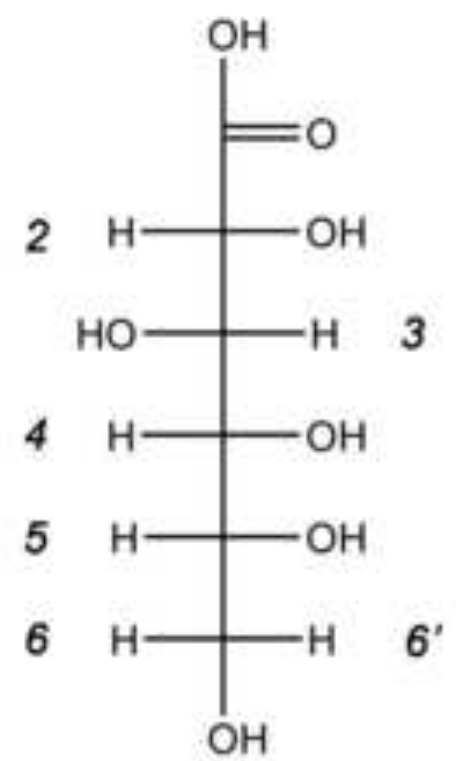




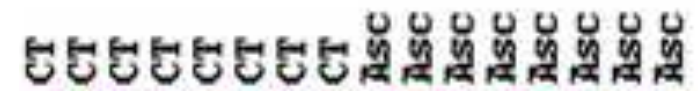

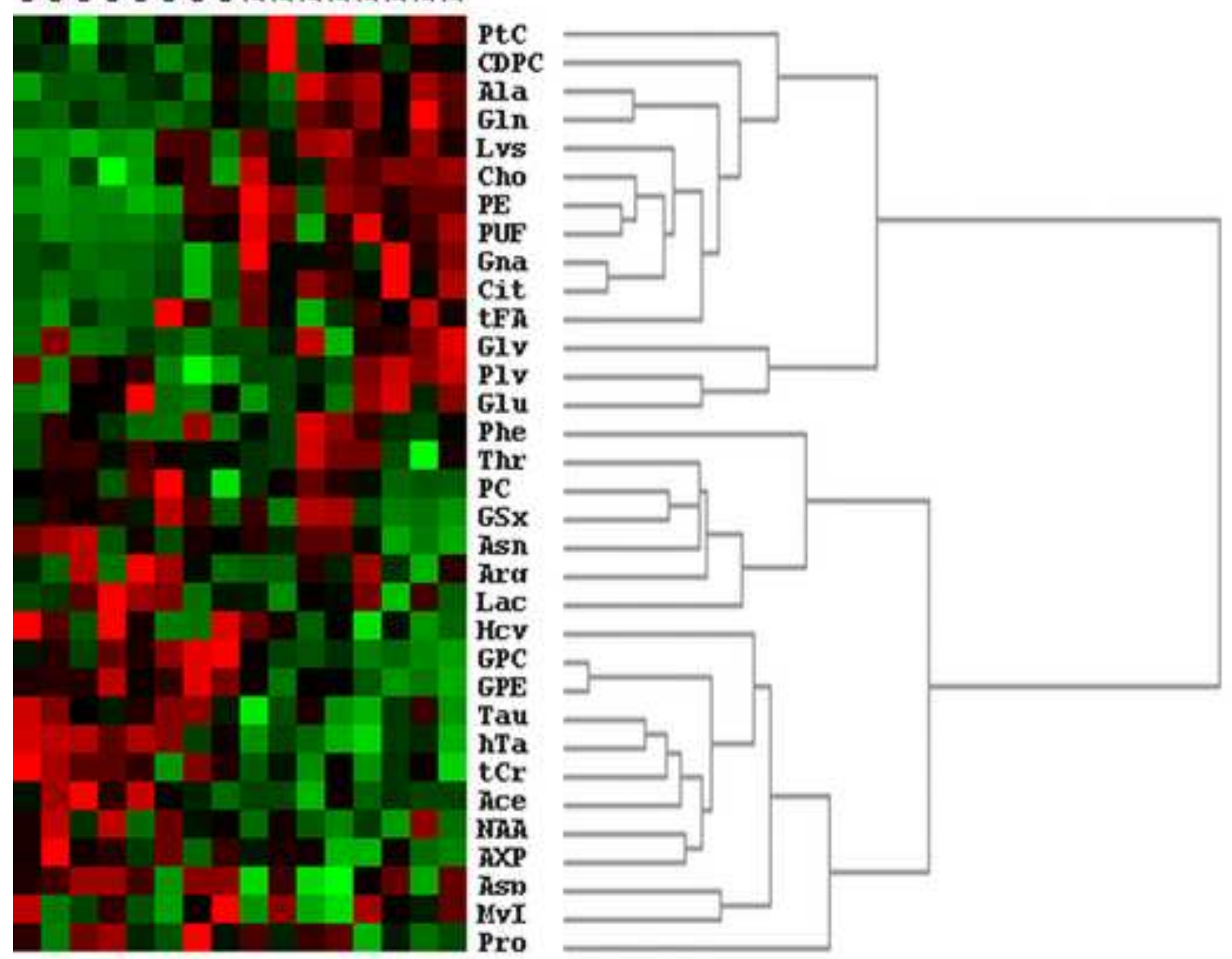

CDPC

Gin

Lvs

Ch

PUF

Git

tFA

Glu

The

GS $x$

Asn

Hev

GPC

hTa

Pro 


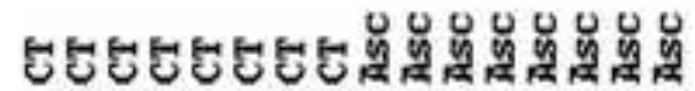

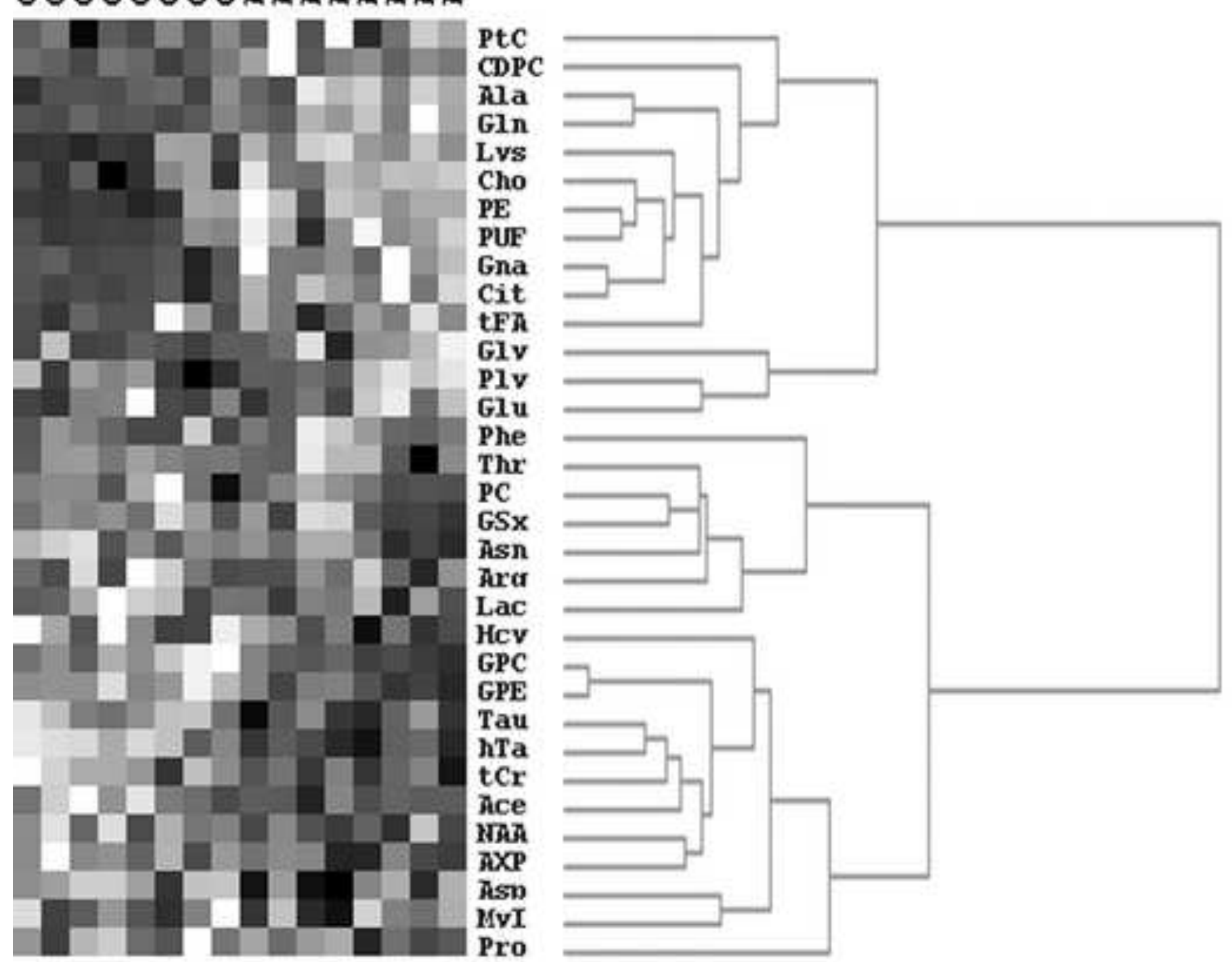




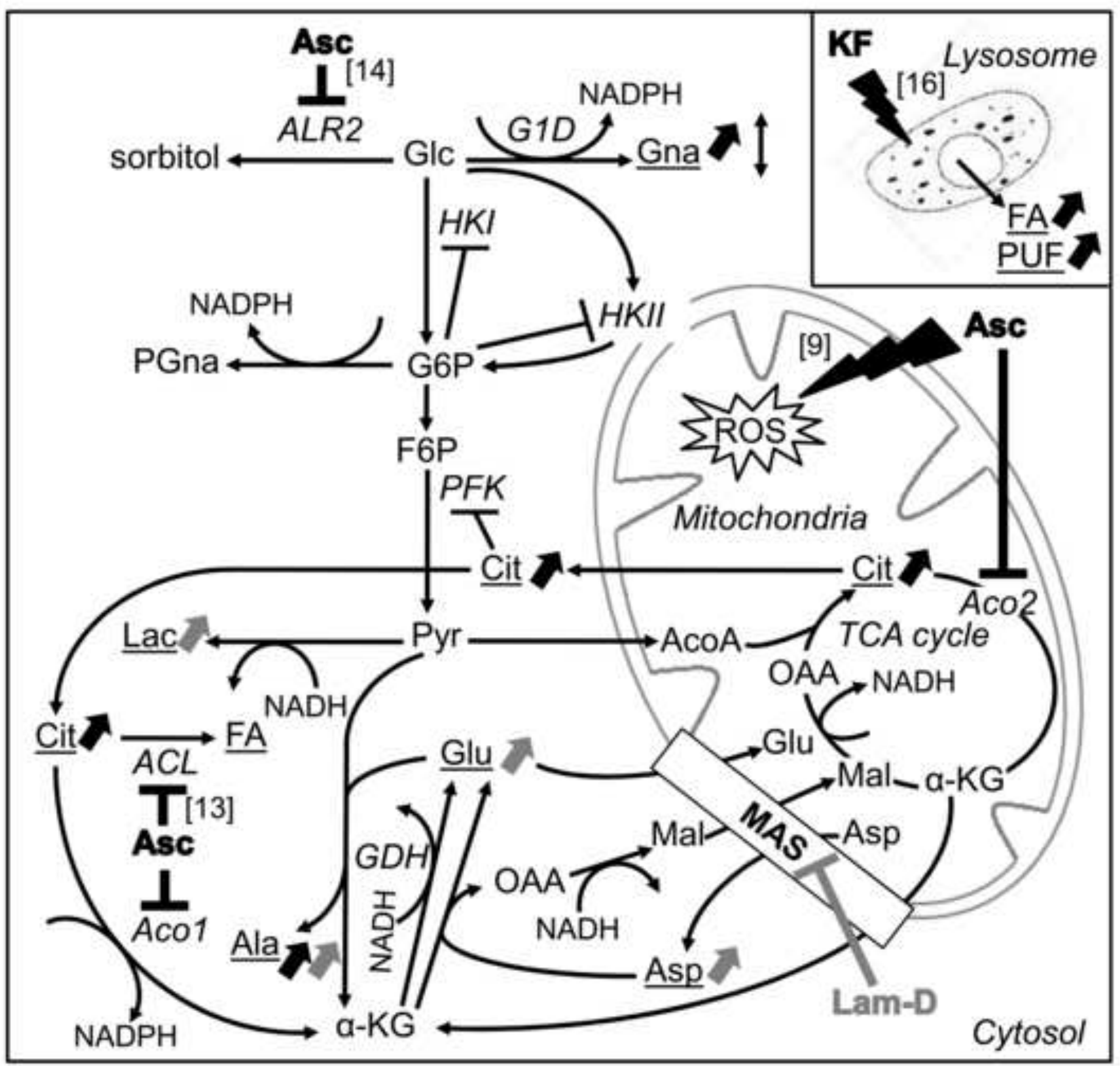

rage 34 or 35 
